DIW BERLIN

Discussion

Papers

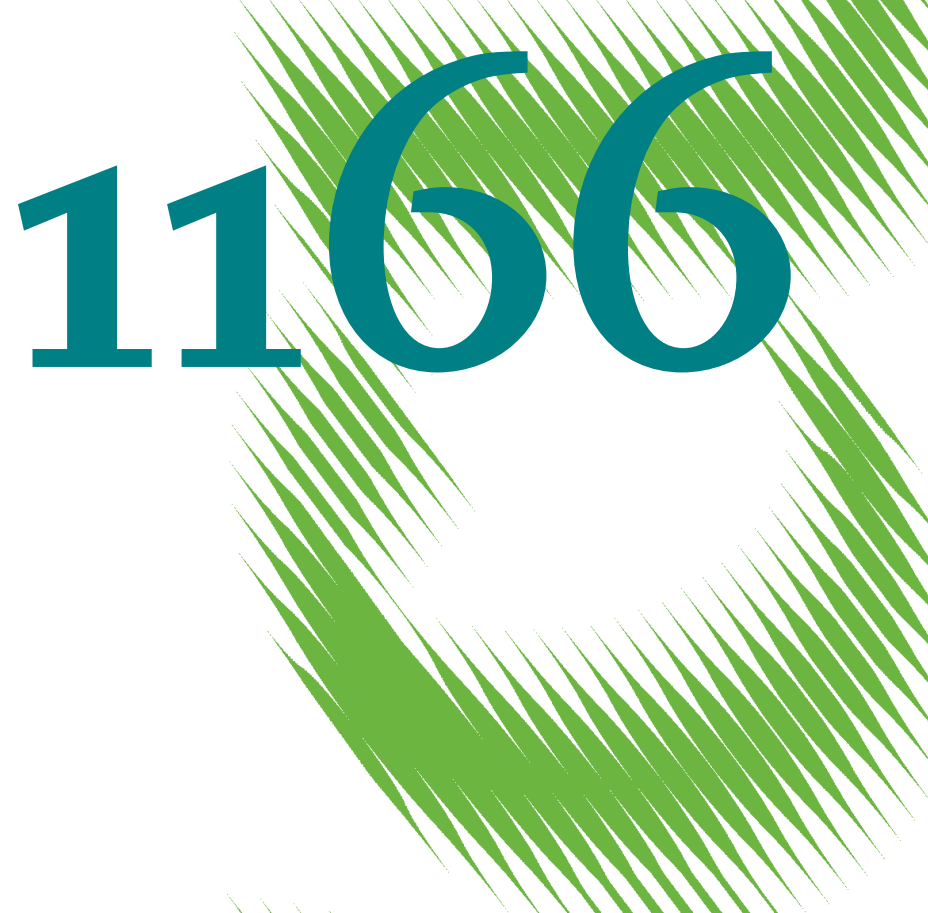

Renewable Electric Energy Integration

Quantifying the Value of Design of

Markets for International Transmission Capacity

K. Neuhoff, R. Boyd, T. Grau, J. Barquin, F. Echabarren, J. Bialek, C. Dent, C. von Hirschhausen, B. F. Hobbs,

F. Kunz, H. Weigt, C. Nabe, G. Papaefthymiou and C. Weber 
Opinions expressed in this paper are those of the author(s) and do not necessarily reflect views of the institute.

IMPRESSUM

(C) DIW Berlin, 2011

DIW Berlin

German Institute for Economic Research

Mohrenstr. 58

10117 Berlin

Tel. $+49(30) 89789-0$

Fax +49 (30) $89789-200$

http://www.diw.de

ISSN print edition $1433-0210$

ISSN electronic edition 1619-4535

Papers can be downloaded free of charge from the DIW Berlin website:

http://www.diw.de/discussionpapers

Discussion Papers of DIW Berlin are indexed in RePEc and SSRN:

http://ideas.repec.org/s/diw/diwwpp.html

http://www.ssrn.com/link/DIW-Berlin-German-Inst-Econ-Res.html 


\title{
Renewable Electric Energy Integration: Quantifying the Value of Design of Markets for International Transmission Capacity
}

\author{
Karsten Neuhoff ${ }^{1}$, Rodney Boyd ${ }^{1}$, Thilo Grau ${ }^{1}$, Julian Barquin ${ }^{2}$, Francisco Echavarren ${ }^{2}$, \\ Janusz Bialek ${ }^{3}$, Chris Dent ${ }^{3}$, Christian von Hirschhausen ${ }^{4}$, Benjamin F. Hobbs ${ }^{5}$, Friedrich Kunz ${ }^{6}$, \\ Hannes Weigt ${ }^{6}$, Christian Nabe ${ }^{7}$, Georgios Papaefthymiou ${ }^{7}$, Christoph Weber $^{8}$
}

Version correct October $2011^{\bullet}$

\footnotetext{
$1 \quad$ Climate Policy Initiative (CPI) / DIW Berlin - e-mail (karsten.neuhoff@cpiberlin.org)

$2 \quad$ Universidad Pontificia Comillas, Madrid

3 Durham University

$4 \quad$ Technische Universität Berlin

5 Environment, Energy, Sustainability \& Health Institute, The Johns Hopkins University and Electricity Policy Research Group, Cambridge University

6 Technische Universität Dresden

$7 \quad$ Ecofys Germany GmbH

$8 \quad$ Universität Duisberg-Essen
}

This paper has been produced in support of the "EU Intelligent Energy Europe program" REshaping project which also funded part of the research along with Climate Policy Initiative. Friedrich Kunz acknowledges support of the RWE research fellowship (RWE Studienförderung). B. F. Hobbs was partially supported by the UK Engineering and Physical Sciences Research Council through the Supergen Flexnet Consortium (EP/E04011X/1), and by the US National Science Foundation (EFRI Grant 0835879). We would also like to thank ENTSO-E for the provision of the raw network data set. 


\begin{abstract}
Integrating large quantities of supply-driven renewable electricity generation remains a political and operational challenge. One of the main obstacles in Europe to installing at least $200 \mathrm{GWs}$ of power from variable renewable sources is how to deal with the insufficient network capacity and the congestion that will result from new flow patterns. We model the current methodology for controlling congestion at international borders and compare its results, under varying penetrations of wind power, with a model that simulates an integrated European network that utilises nodal/localised marginal pricing. The nodal pricing simulations illustrate that congestion - and price - patterns vary considerably between wind scenarios and within countries, and that a nodal price regime could make fuller use of existing EU network capacity, introducing substantial operational cost savings and reducing marginal power prices in the majority of European countries.
\end{abstract}

Keywords: Power market design, renewable power integration, congestion management, transmission economics 
European energy targets are expected to foster an increase of some $200 \mathrm{GWs}$ of renewable generation capacity by 2020 . A main obstacle to large-scale renewable integration within Europe is insufficient network capacity and the congestion problems that will result, given that new generation will be required to share transmission capacity with the existing generation portfolio.

In addition, significant investment in network extensions will be required to adequately integrate increased renewable energy. Again, effective use of the existing network can reduce the need for network extension, can provide flexibility to more fully utilise the network, and can offer a transparent price signal to inform TSOs and regulators of the location of needed network expansion projects, and perhaps contribute to public acceptance of such projects.

Congestion represents the situation when technical constraints (e.g., thermal line limits, and voltage stability constraints) or economic restrictions (e.g., priority feed-in or contract enforcement limits) are binding and thus restrict power transmission between regions. Congestion management aims at obtaining a cost optimal power dispatch while accounting for those constraints. The EU and some US states have adopted two contrasting approaches to address congestion in their market designs: the EU has opted for expansion on market coupling as proposed by ERGEG (2010), while five regional markets in the US have adopted locational marginal pricing (LMP), also called nodal pricing (O'Neill et al., 2005).

As zonal pricing does not capture the actual state of grid flows and congestion, it fails to provide information that is necessary to inform regulators, transmission operators and the public about the need for transmission reinforcement and investment. While other papers have discussed the relative benefits of nodal pricing compared to zonal pricing with market coupling, ${ }^{1}$ the purpose of this paper is to quantify whether improving system design makes better use of the network capacities in the EU (UCTE, now called ENTSO-E).

\footnotetext{
${ }^{1}$ Schweppe et al. (1988) and Hogan (1992) have shown that nodal prices lead to higher social welfare than zonal prices, let alone country-wide uniform prices. Other theoretical papers argue that a system using nodal pricing accommodates renewable energy sources more efficiently and can provide increased stability to the system. The TradeWind (2009) and EWIS (2009) studies discussed system needs for large-scale wind integration, but did not compare net transfer capacity (NTC) and nodal pricing regimes. Leuthold et al. (2008) have shown the superiority of nodal pricing for the integration of wind into the German network. Other estimates of cost savings from using full network models and nodal pricing rather than zonal pricing and aggregate intercountry transfer capacity are provided by Barth et al. (2009) and van der Weijde and Hobbs (2011). See the discussion of the literature in Section 4.1.
} 
To that end, we utilized an EU power market dataset (the UCTE-Study Model) and used three models for calculation: the ECOFYS model (Ecofys ${ }^{2}$ ) to calculate nodal prices; and the MADRID (Universidad Pontificia Comillas) and DRESDEN (Dresden University of Technology) models to calculate the differences between nodal pricing and zonal pricing resulting from the traditional Net Transfer Capacity (NTC) approach, which is defined in the Annex, where a detailed description of the models can also be found.

The results of the nodal system simulations using the DRESDEN and MADRID methods can be summarized as follows:

- Zonal-national boundary variations. The calculations show that under a nodal pricing structure, price zones do not conform to country borders and vary depending on the amount of wind output. The implication is that zonal pricing methodologies do not capture the physical reality of the grid; the zonal approach requires stable regions with homogenous price levels and thus creates considerable redispatch costs and gaming opportunities.

- Congestion dynamics under varying wind scenarios. The variation in distribution of congestion under different wind scenarios suggests that zones have to be very small if congestion within zones is to be limited, illustrating the need for nodal pricing.

To determine the difference between a nodal pricing regime and the current EU system, the simulated nodal results were then compared to a second set of simulations representing implicit auctions with joint allocation of transmission capacity (NTC) across all international links, i.e., the optimization of the current paradigm pursued by European Regulators (ERGEG, 2010). For this purpose, the models first calculated the volume of total transmission capacity (TTC) based on the calculation methodology presented in ENTSO-E documents and reported by TSOs in interviews that were undertaken as part of this research. This provided TTC values that were consistent with the model network and were used as a base for the simulation of market results (using the MADRID and DRESDEN methods) from the day-ahead market with subsequent redispatch where necessary. We then evaluated the differences between the nodal and zonal approaches as determined in the models. The main conclusions of this comparison are as follows:

- International transfers. The nodal pricing approach leads to an increase of up to $34 \%$ in international MW transfers between countries, depending on wind power penetration. This means that the existing network capacity can adequately accommodate

\footnotetext{
${ }^{2}$ The Ecofys model is an OPF model based on the MATPOWER simulation package (MAT09, 2009).
} 
increasingly large volumes of intermittent energy sources. The sum of all cross-border transfers reaches $43 \mathrm{GW}$ at maximum wind output, in both the Dresden and Madrid models.

- Cost savings. Annual savings of system variable (mainly fuel) costs under a nodal pricing structure range from $€ 0.8$ - $€ 2.0$ billion depending on the penetration of wind power. This is represents an average of $1.1 \%-3.6 \%$ of operational costs can be saved. These results are in line with empirical values from the USA and the results of a simulation model for a small-scale network. These do not include possible savings in unit commitment costs such as start-up and minimum run costs, which were not calculated.

- Country level marginal prices. Weighted marginal prices are lower under a nodal pricing regime in $60 \%$ to $75 \%$ of EU countries. Real-time congestion mitigation measures such as wind spilling, load shedding and power plant re-dispatching are relatively costly options, the uses of which are minimized under a nodal approach.

The paper is organized as follows. In Section 2 we look at the issues related to congestion management in an environment of increased renewable energy: this includes a survey of literature and previous studies. Section 3 provides a summary of the data used and the simulation results, with a discussion following in Section 4, including a comparison with other studies. Section 5 presents conclusions. The Annex describes existing methodologies for calculating international transfer capacities, and then introduces the nodal pricing and the NTCconstrained dispatch models that we have developed for this paper. 


\section{Survey of Issues: Review of Solutions to Congestion Management}

\subsection{Studies on Congestion Management Mechanisms}

Congestion management is a key element of market design. The main issues are how transmission capacity is allocated in times of shortages, and methods for coping with congestion efficiently.

In general, congestion management mechanisms can be classified into transmission capacity allocation and congestion alleviation methods (Androcec and Wangensteen, 2006; Brunekreeft, et al., 2005):

- Transmission capacity allocation methods aim to optimally allocate existing capacity among potential users. The methods can be grouped into either explicit auctions (first come, first served; pro-rata rationing; explicit auctions), or implicit auctions (bilateral implicit auctions; market splitting, market coupling, nodal pricing). Furthermore, a differentiation can be made according to the way that physical power flows are taken into account: non-flow-based methods assume that electricity can be transported between specific locations in the grid without violating physical constraints whereas flow-based methods respect the grid's actual physical constraints. Figure 1 provides an overview of these congestion management mechanisms.

- Congestion alleviation methods aim to manage existing or expected congestion using redispatching of power plants and counter trading.

In fact, many power market designs combine approaches to avoid the need to alleviate congestion, e.g., by defining capacity available for international commercial transactions so that congestion within countries is eased.

In Europe, solutions to relieve cross-border and inner-country congestion focus on coordinated market coupling or splitting (Ehrenmann and Smeers, 2005). Market coupling assumes that submarkets already exist and cannot be merged into one integrated market in the short- or medium-term. If there is no congestion, the prices in the sub-markets are set equal; otherwise, the prices can separate. Market splitting assumes an existing integrated market where injections and withdrawals of several nodes are assigned to a specific zone in case of congestion. A third approach, coordinated explicit auctions, also attempts to interlink different markets. In this case transmission capacity and energy is traded on separate markets. 
A well-known engineering solution to congestion management is to use an Optimal Power Flow (OPF) optimization tool (Wood and Wollenberg, 1996) which optimally, i.e., at minimum cost, redispatches generators in a network to relieve congestion. OPF has been widely used since the late 1960s, well before the advent of liberalization, by vertically integrated utilities which were able to control directly the generators they owned. A realization by Schweppe et al. (1988) that so-called Lagrange multipliers, which are a by-product of OPF, have an economic interpretation of nodal shadow prices was a break-through that made it possible to introduce market-based power system operation. The shadow prices (often referred to as the Locational Marginal Prices or LMPs) reflect the marginal cost of increasing generation or demand at any node in a secure way, i.e., without violating any transmission constraint included in the model. It can be proven under mild conditions that generators facing the nodal prices would maximize their profit by generating the level required by OPF (assuming price-taking or competitive behaviour). Economists refer to such prices as 'equilibrium supporting prices' (O'Neill et al., 2005) In other words, market-based prices achieve the same goal of congestion management as the direct command of generation by traditional vertically-integrated utilities. This way the prices are compatible with, and are an integrated part of, optimal and secure power system operation.

It is important to emphasize that practically all utilities, including the vertically integrated ones, use OPF as an engineering tool to manage congestion. As LMPs are a by-product of OPF, they are readily available for use to settle spot power markets.

"Security-constrained, economic dispatch with locational marginal pricing" (Hogan, 1992) is now used by many restructured electricity markets, such as Australia, New Zealand and Chile. In the US, five restructured markets have adopted locational marginal pricing: PJM-MISO, New England ISO, New York ISO, ERCOT (Texas), and the Californian ISO (O'Neill et al., 2008). The US experience illustrates that small variations in the formulation of the optimization model that clears the market and subsequent calculation of settlements can change the amounts paid by individual generators and groups of consumers and can lead to disputes. Just a few examples of auction and settlement design choices include: whether start-up costs are repaid if otherwise generators would lose money under the energy prices they are paid; whether such start-up payments are recovered from consumers by adding them to peak prices or spreading over all energy sales; and whether domestic consumers are exposed to nodal prices or an average regional price. Up-front consideration of these specific market design decisions, and consistent application of the chosen design across European countries, can facilitate implementation and integration of power markets. 
Figure 1: Evolution of CM mechanisms.

Source: Vujasinovic et al. (2005, p.3), Leuthold (2006, p.6), ETSO (2007, p.6).

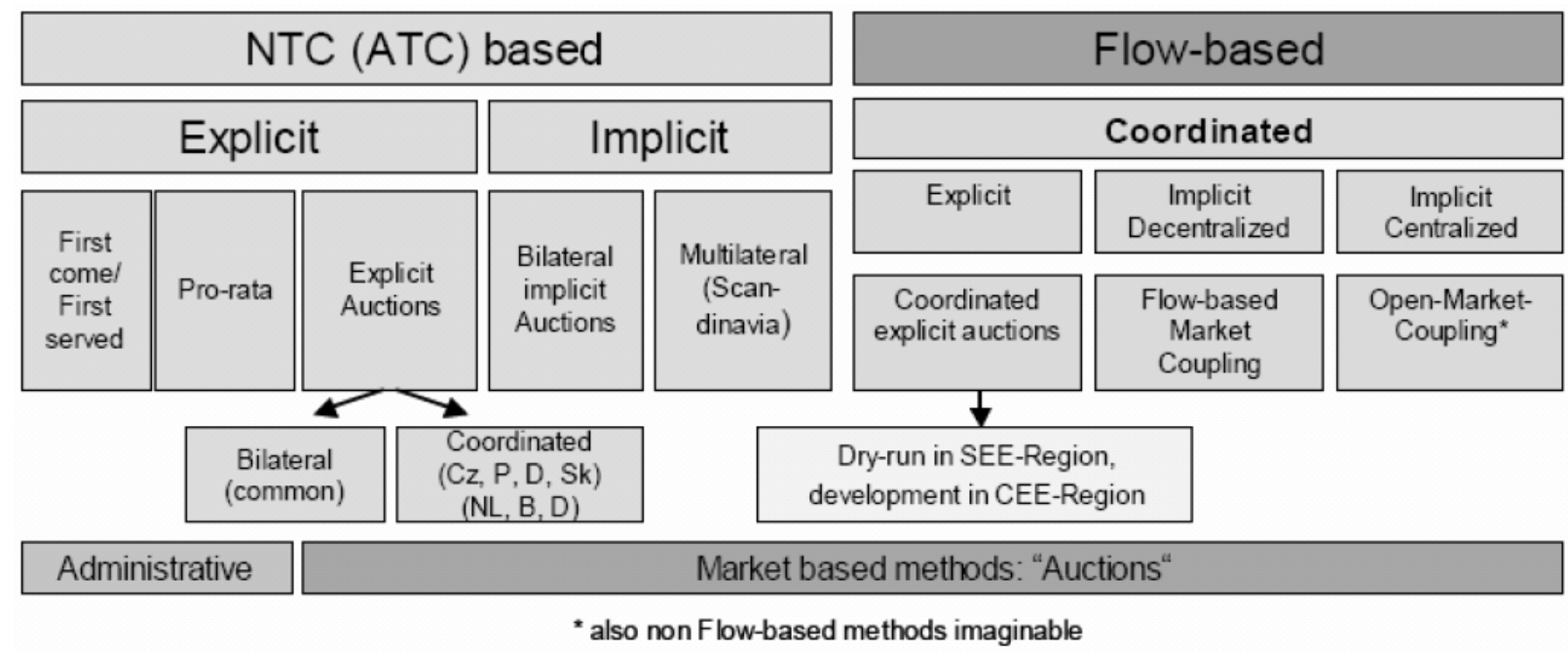

\subsection{Security Issues}

Power system security has always been the main focus of grid operators in their daily operation. The two most important facets of power system operation affecting security are the following:

- The lack of significant storage capacity requires short-term management of the generation/demand balance.

- In a meshed transmission network, such as the one discussed here, power flow along a line is the outcome of the overall pattern of generation and demand in the whole system. For instance, the overall system generation/demand pattern has to be changed if any of the transmission lines are overloaded - this adjustment is referred to as redispatch.

Many examples illustrate the importance of the integrated approach to power system operation. Although the large-area power system blackouts in 2003 (US/Canada, Italy) and the so-called UCTE disturbance in 2006 were caused by rare events, the reason they affected such large areas was the insufficient coordination of operation between the TSOs involved (Bialek, $2005,2007)$. Direct economic losses caused by the blackouts were in the range of billions of Euros.

The original reason for interconnecting individual control areas or countries was to minimize the requirement for a back-up generation reserve should any generator trip, and to provide 
better frequency response. The required whole system reserve is much smaller than the sum of individual reserves if each control area was to operate separately. Frequency variations also tend to be much smaller in a bigger system due to a higher overall inertia of generators. Prior to liberalisation, the capacity of interconnecting tie-lines tended to be limited as they were necessary only for back-up purposes or for limited and controlled cross-border trades. That situation changed in the 1990s with liberalisation of the electricity supply systems in Europe and elsewhere. The tie-lines have been increasingly utilized, facilitating an explosion in crossborder trades. This has resulted in a significant congestion in Europe: 12 out of 24 interconnectors in Europe are permanently or frequently congested, 5 are occasionally congested and only 7 seldom or never congested (EC, 2003). On top of that there is also congestion in internal networks within each country.

The level of congestion will increase as investment in renewable power generation is pursued to deliver the $20 \%$ renewable energy target by 2020 , which implies significantly higher shares of renewable electricity. Renewable generation is generally highly intermittent - the average load factor of on-shore wind farms is about $20-30 \%$, while the load factor of off-shore wind farms tends to approach $40 \%$. Consequently it is not economically sensible to upgrade the transmission networks to handle the full capacity of wind farms as the networks would be rarely fully utilized. This means that at times of high wind, transmission networks are likely to exhibit more severe congestion, and therefore efficient sharing to facilitate least cost generation to meet demand will become more important.

\subsection{Studies Focusing on Wind Integration: TradeWind and EWIS}

Two comprehensive studies have been carried out recently on the impact of wind on European network development: the TradeWind study (TradeWind, 2009), which is an Intelligent Energy Europe (IEE) project led by the European Wind Energy Association (EWEA), and the European Wind Integration Study (EWIS, 2010), which was a joint project between European TSOs, cofunded by the European Commission. The EWIS study focuses on short term actions for network development with emphasis on the expected situation in 2015 and an outlook to 2020, whereas the TradeWind study simulates the integration of wind scenarios until 2030.

While the wind scenarios in both studies are very similar, the studies differ with regard to the methodological approaches and the underlying datasets: the EWIS study examined a small set of robust Point-in-Time situations to evaluate European-wide coordinated measures in great 
detail based on the "UCTE reference data set" from the participating TSOs. ${ }^{3}$ In contrast, the TradeWind study had to rely on a simplified UCTE network model (with network areas defined mostly on country basis), which is available in the public domain (Zhou, 2005). The EWIS study was able to perform a detailed analysis, e.g., of voltage problems and internal congestion, but was not able to quantify the importance of these problems, for instance in terms of number of critical hours of a year. On the other hand, the annual chronological production simulation performed in TradeWind shows the frequency of overload situations.

Based on a cost-minimizing dispatch, the impact of market design and transfer capacities between countries could be analysed by these studies, providing several useful insights:

- The EWIS study suggested that internal congestion was significant in the examined snapshot simulations.

- A temporary curtailment of wind could avoid line overloading and lead to an overall cost reduction.

- The TradeWind study identified 42 onshore interconnectors and a corresponding time schedule for upgrading that would benefit the European power system and its ability to integrate wind power. Reinforcing these lines should lead to substantial cost savings in total system operation costs of $€ 1,500$ million/year for 2020 and 2030. In those years, congestion can be expected to increase on the borders of France, between the UK and Ireland and on some of the Swedish, German and Greek borders. An interlinked (meshed) offshore grid could link future offshore wind farms in the North Sea and the Baltic Sea and the onshore transmission grid.

- TradeWind's preliminary economic analysis based on an installed wind power capacity of $125 \mathrm{GW}$ shows that this system compares favourably to a radial connection solution where wind plants are only connected directly to the onshore grid. Allowing for intraday rescheduling of cross-border exchange will lead to savings in operational costs in the order of $€$ 1-2 billion per year compared to a situation where cross-border exchange must be scheduled day ahead (TradeWind, 2009). This suggests that interconnector capacities should be allocated directly via implicit auction.

While the existing simulation studies for the European grid have assessed the value of transmission capacity, and the implications of explicit versus implicit auctions as means to grant access to international interconnectors, this study now also assesses the implications of congestion within countries and how they impact on the choice of market design.

\footnotetext{
${ }^{3}$ This dataset contains the full network information and is also used for the day-ahead congestion forecasts. Its level of detail allows performance of $\mathrm{N}-1$ security analysis and the evaluation of voltage profiles.
} 


\subsection{Methodologies for Calculating International Transfers}

Before we turn our attention to calculating the efficiency of various models for international capacity allocation (a key component of congestion management), the processes and definitions relevant for international capacity allocation are outlined in the Annex, in which also lies the technical description of the models used. Of particular relevance to this section, however, is the concept of Net Transfer Capacity: the maximum possible transfer between two systems without violating security requirements. Maximising NTC maximises international capacity allocation. International capacity allocations distinguish between commercial transfer limits (which are used by market participants to plan their cross-border trades), and physical values (as used by system operators in real-time operation (ETSO, 2001a)).

\subsection{Case Study Data}

We use the UCTE-Study Model (UCTE-STUM) dataset, which was provided by ENTSO-E for research purposes. The UCTE-STUM is a limited version of the UCTE reference data set for each seasonal period produced for third-party analysis.

The dataset comprises a forecast for the static operation of the UCTE control area for the 3rd Wednesdays in January for the year 2008 and includes a detailed representation of the former UCTE network of approximately 4,300 buses, 6,300 lines and 1,100 transformers together with their loads and generation in-feeds. The dataset allows the calculation of the AC load flow for the respective snapshot of the system operation. Being a tool dedicated to perform AC power flow calculations, the UCTE-STUM dataset has important limitations:

- The model does not contain geographic (latitude-longitude) information on the network nodes,

- Transmission lines have been aggregated to equivalents, especially parallel circuits and medium voltage distribution networks,

- Transmission capacities are partly missing or are in some cases implausible,

- Information on generator characteristics are not provided, and

- Loads and distributed generation have been aggregated for each node.

To perform network studies, the UCTE-STUM dataset was enhanced to allow dispatch optimization. Specific actions were undertaken to address the above data limitations. 
The geographic locations of nodes were identified in a manual process based on the public ENTSO-E network map, using the abbreviations provided by the UCTE-STUM dataset. In Figure 2 , the result of this mapping is presented, where different line colours are used for the different voltage levels and equivalent elements are represented with dotted lines.

A European generation database was matched to the nodes including power plants with capacities exceeding $100 \mathrm{MW}$. The matching was performed on the basis of geographic proximity and according to information provided at the public ENTSO-E network map. The total installed capacity amounts of approximately $430 \mathrm{GW}$, comprising 10 generation technologies, is presented in Figure 3. To counterbalance the impact of distributed generation, nodal loads were increased pro-rata on a country basis, based on the load values published on the ENTSO-E website. The derived total system load for the obtained snapshot amounts to approximately $300 \mathrm{GW}$.

Wind feed-in scenarios were calculated and matched to the network nodes based on the "high scenario 2008" of the TradeWind study (TradeWind 2009, pp. 21). Beside a scenario without wind production, three wind production snapshots (high: $38 \mathrm{GW}$, medium: $13 \mathrm{GW}$ and low: $1 \mathrm{GW}$ ) were selected as representative scenarios of the total wind feed-in in the system corresponding to a total installed wind capacity of approximately $63 \mathrm{GW}$. The derivation of these snapshots from the aggregate wind power distribution is presented in Figure 4. Transmission lines were de-rated to $80 \%$ of their nominal capacity to approximate the $\mathrm{N}-1$ security constraints in the network. Finally, transmission lines with unrealistic or missing capacity values were adjusted to realistic values. 
Figure 2: Network model geographic representation. Different line colours represent different voltage levels (red: $380 \mathrm{kV}$, cyan: $220 \mathrm{kV}$, blue: $150 \mathrm{kV}$ ) and dotted lines correspond to equivalent elements.

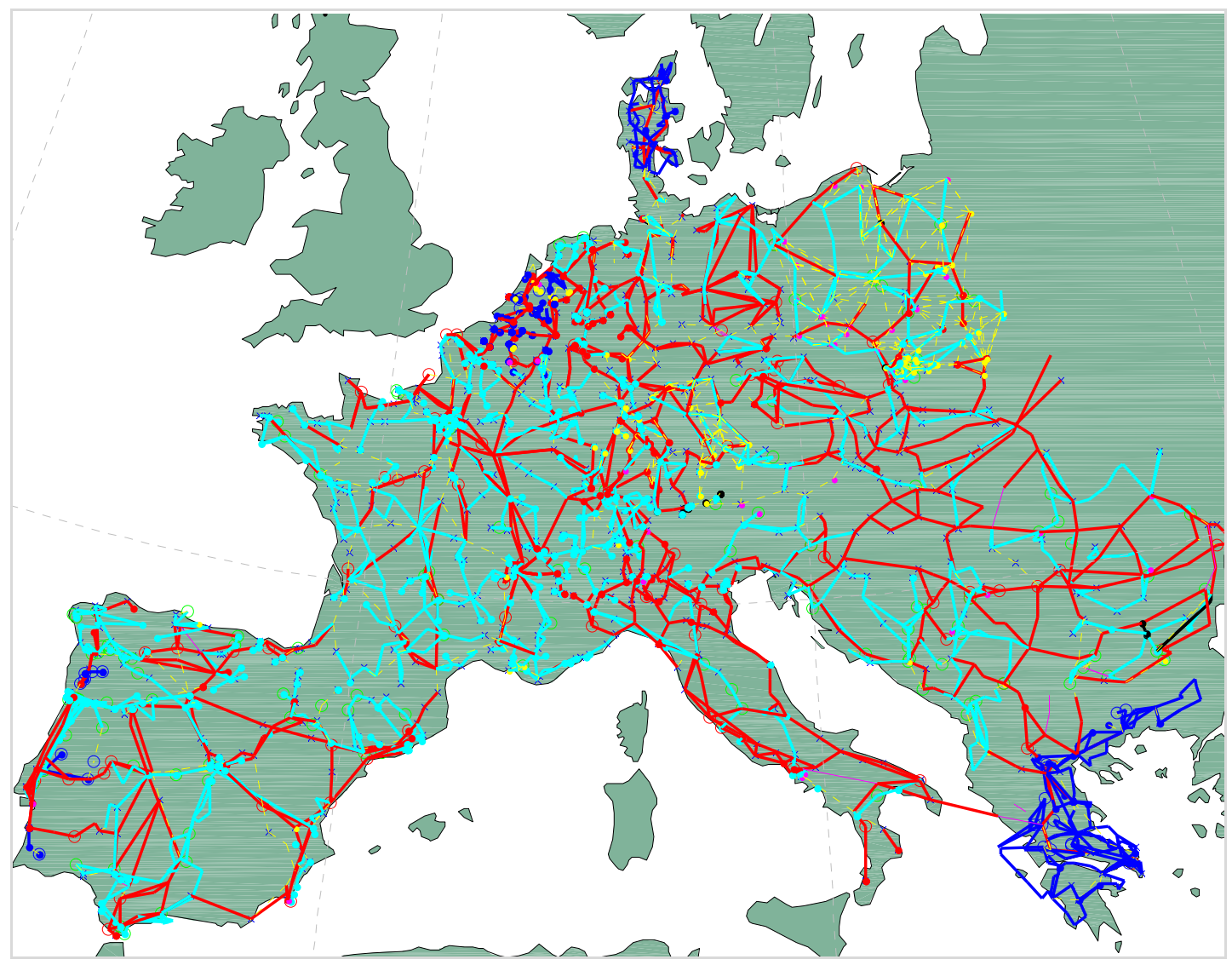


Figure 3: Generation technologies mix used in the models.

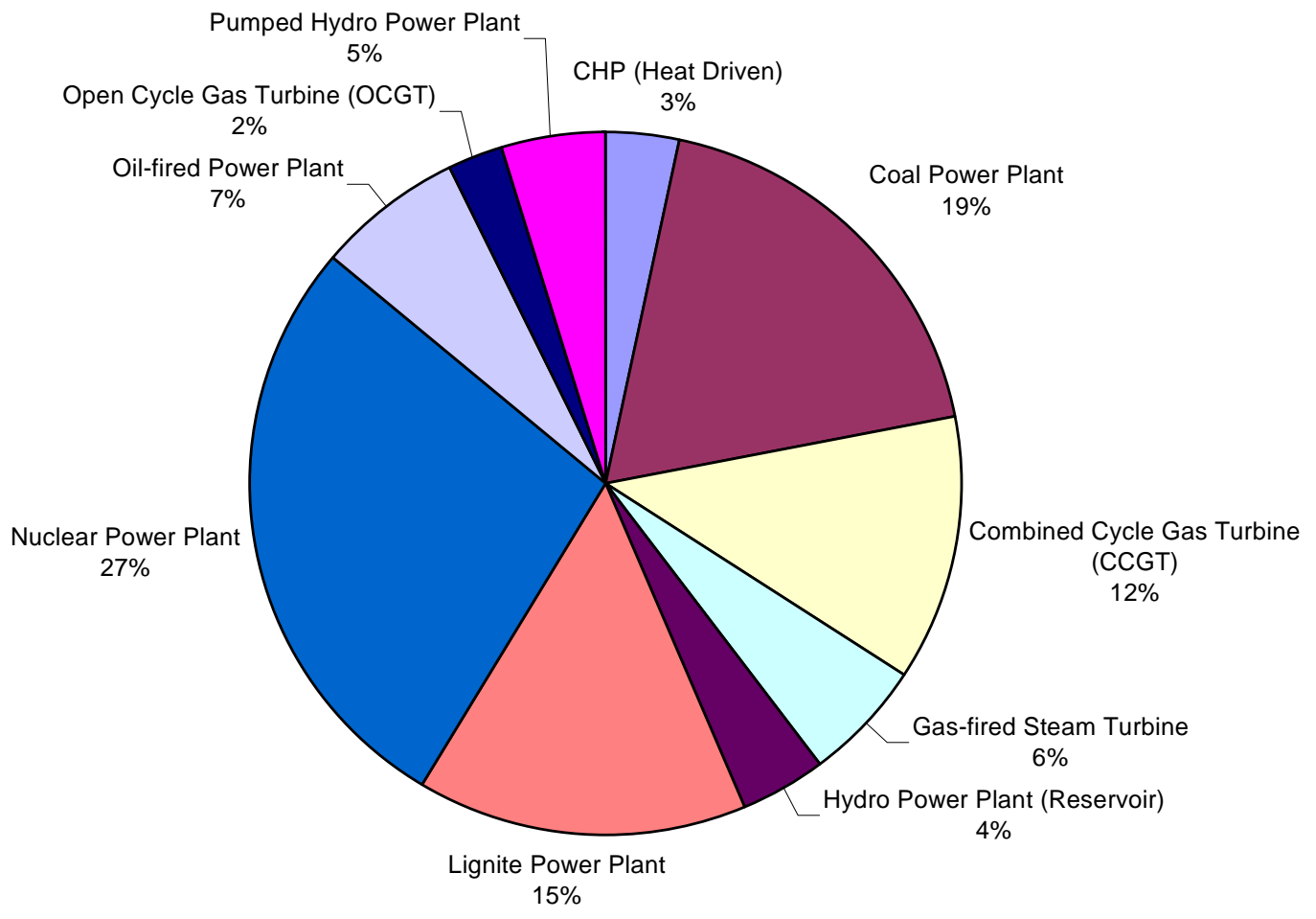

Figure 4: Distribution of the aggregate wind in-feed for the $2008(H)$ TradeWind scenario and the respective snapshots.

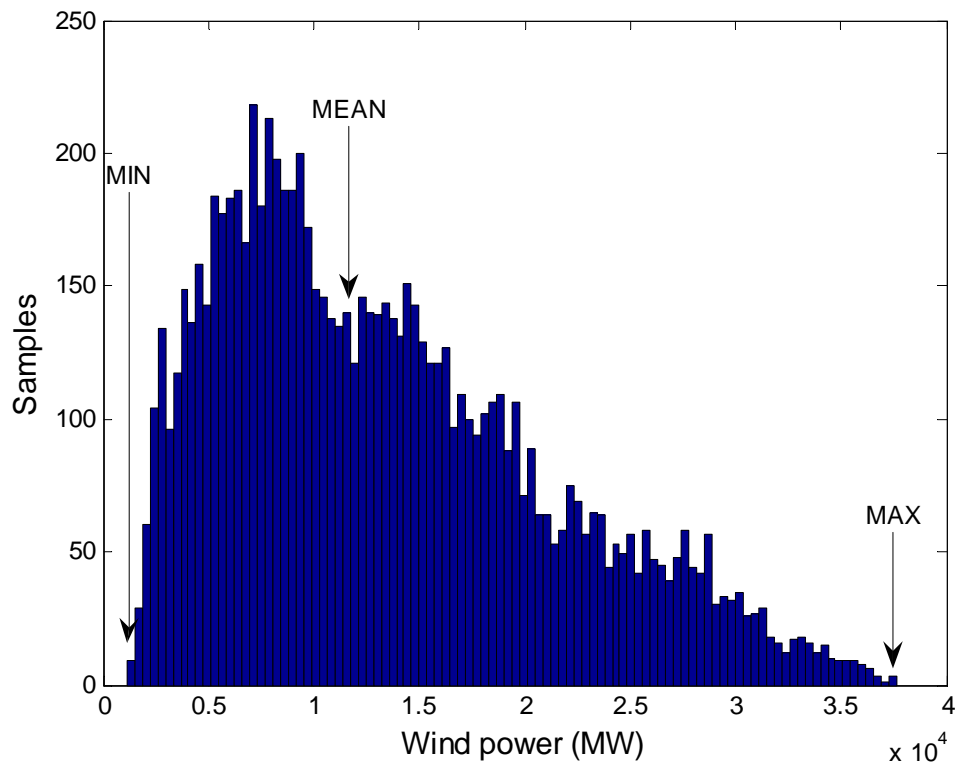




\subsection{Comparing nodal pricing simulation results}

We start by comparing the results from the DRESDEN and MADRID models to simulate nodal prices under different wind penetration scenarios across the observed region. In Section 3.4, we will simulate implicit allocation of transmission capacity across Europe. Subsequently, we compare the two sets of simulations in Section 3.5 to derive conclusions concerning the effect of nodal pricing on system costs and network utilization. We also evaluate the price levels resulting from the models, comparing them as well to actually observed prices in the current EU system.

Figure 5 (DRESDEN \& MADRID) depicts the volume weighted nodal price by country as an indicator of the prices that would be experienced under nodal pricing (and ultimately added to transmission, distribution, and administrative costs and then passed on to final consumers). The estimated price level in Madrid is lower - because all units are operating - while the Dresden model includes a unit commitment algorithm, which results in less capacity on line and higher marginal costs. However, the Dresden solution has lower total costs than the Madrid solution if all commitment (start-up and minimum load) costs are considered.

For the countries in Figure 5, data on day-ahead market prices was available for comparison, indicated by bars. A range of priced products are available and offer some insights for the hour of the reference case (10 a.m.-11 a.m., Wed. 16-Jan-2008). The day-ahead spot price for that hour is closest to the specific situation of network and generation assets, but additional factors (contract positions, intraday changes to dispatch) might have impacted the price or network configuration. Hence, we also depict the average price for this hour across all Wednesdays in the month to abstract from specific aspects of the day, and the peak price in the day-ahead market to abstract from specific aspects inherent in the hour. The overall price levels are similar between simulated and observed prices, with the largest discrepancy occurring in Austria. This can be attributed to the complex congestion structure combined with the impact of international flow patterns in Austria (see Figure 8). ${ }^{4}$

\footnotetext{
${ }^{4}$ We also confirmed that flow patterns observed in the simulation corresponded to the expectations of the participating power system experts from Spain, Germany and UK. When interpreting the data, it is important to account for the approximations used in the parameterization of individual lines that were not already characterized in the ENTSO-E data set. Furthermore, the future siting of wind turbines is likely to differ from the projections used in the model. Hence the model results do not provide an accurate representation of future congestion of specific lines, but can only capture the general structure of congestion in the network.
} 
Figure 5: Comparison of selected actual market prices for power products for Wednesday 16 January 2008 (bars) and simulated prices (DRESDEN, MADRID).

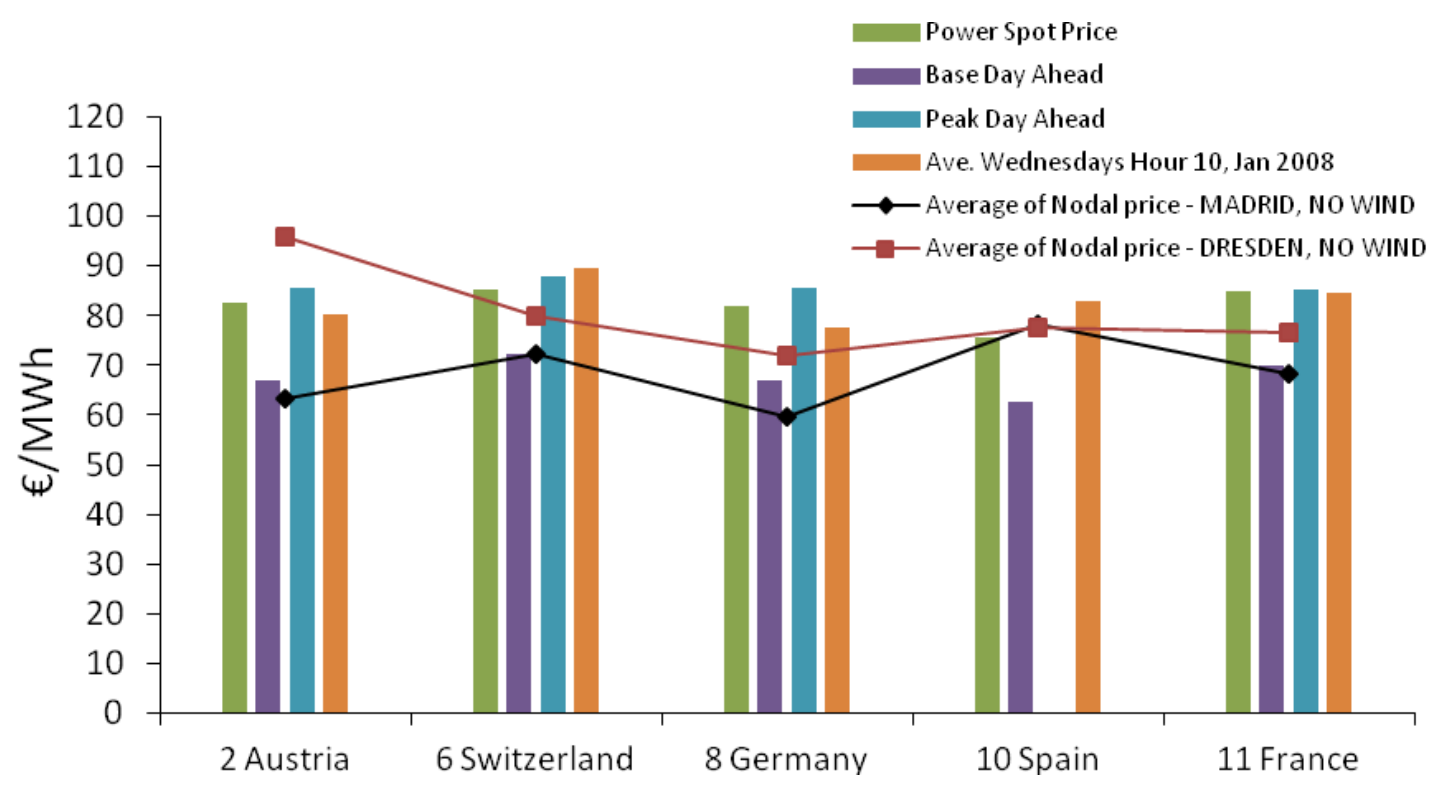

Figure 6 depicts the distribution of the loadings of all the system branches for the max wind scenario. About 50 out of about 6,000 branches are loaded up to their limit, the majority of which correspond to branches within zones (internal congestions). In particular, only 2 branches are cross-border lines while 6 are HV transformers ${ }^{5}$. In Figure 7, the line loadings for the European network for the respective scenario are presented, where the geographic extent of congestion can be seen.

\footnotetext{
${ }^{5}$ As will be discussed later in the section, international flows in the NTC modelling case decrease by $14 \%$ - $34 \%$ relative to the nodal pricing case. This suggests that in the current NTC-based power market design, the number of physically constrained lines between countries is lower than simulated here.
} 
Figure 6: Distribution of branch loads (as a fraction of capacity) for the analysed high wind scenario.

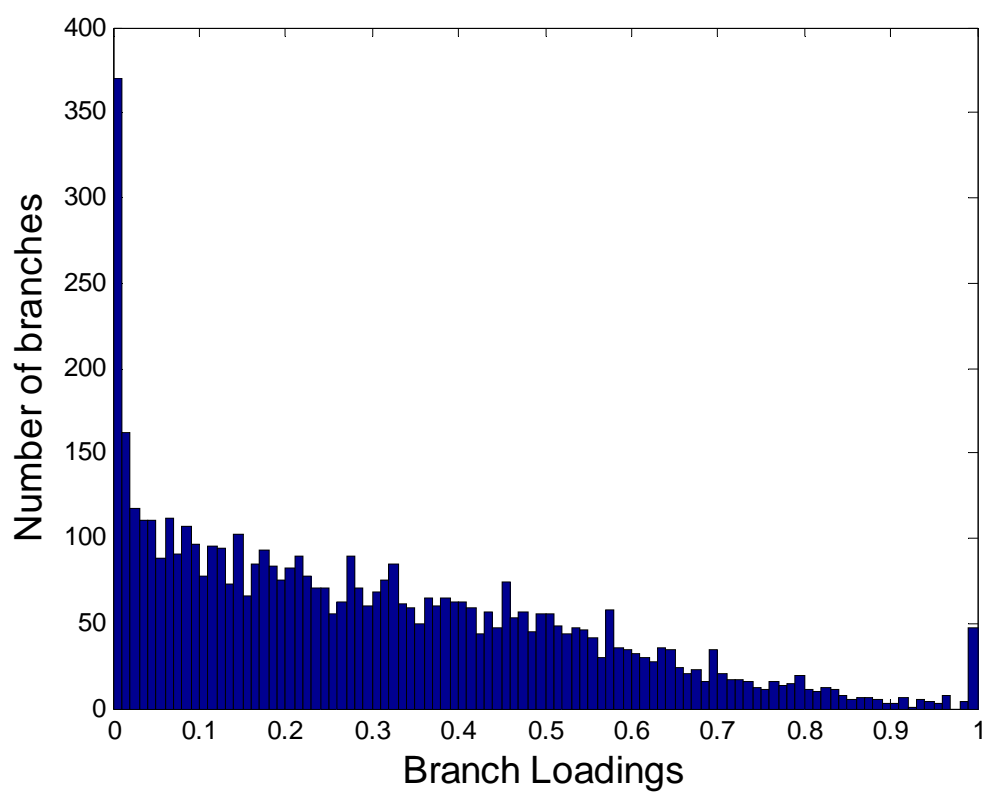

Figure 7: Line loading representation for the maximum wind scenario. In this representation, the line loading is depicted with a respective colour: from blue colour (not loaded) to red (congested lines).

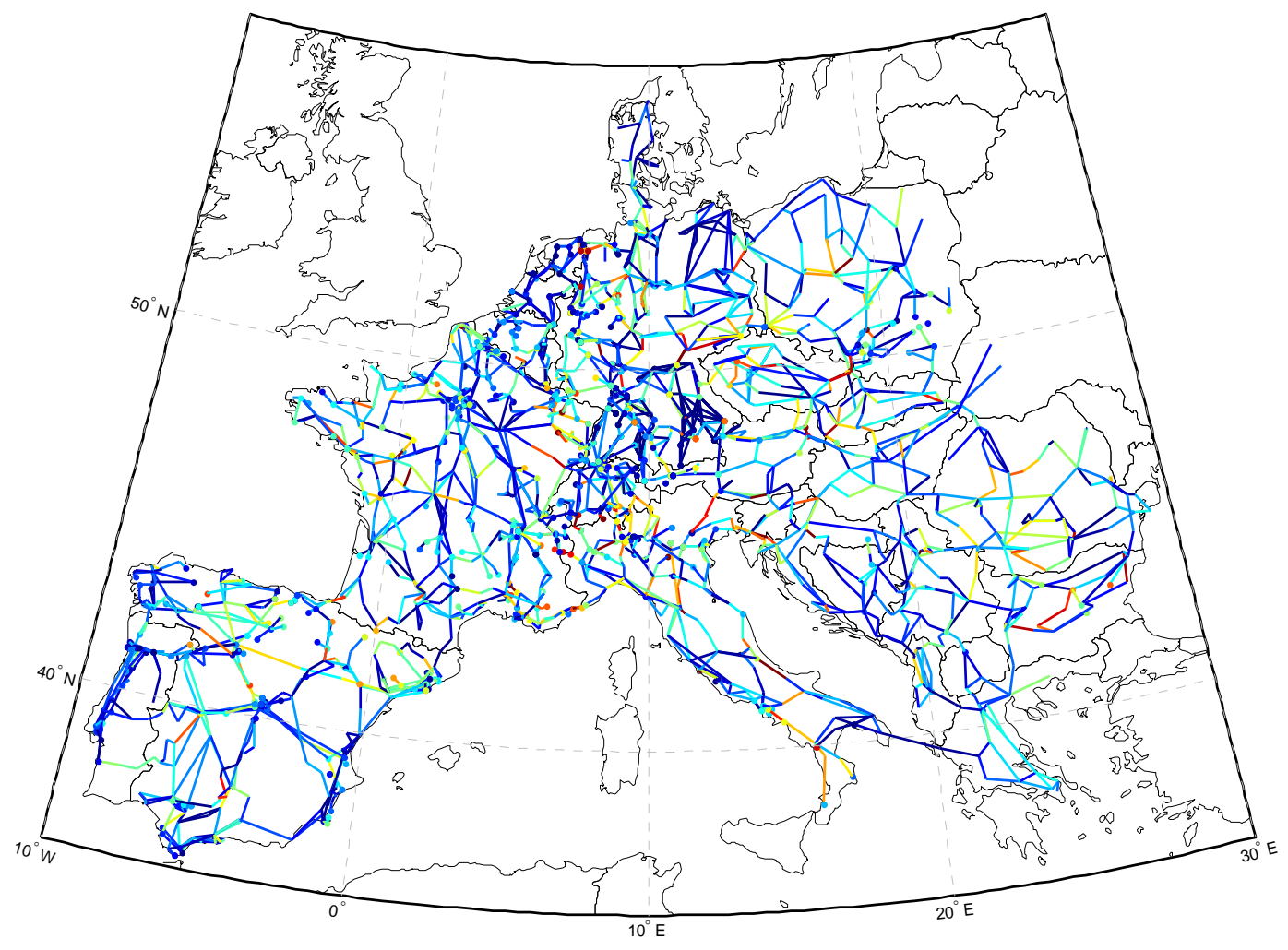


In Figure 8, the nodal price distribution within Europe for two operational snapshots, the no wind case and the maximum wind case, are presented. The calculations show the existence of uniform price areas in Europe that do not necessarily match the national borders. The impact of wind integration in Northern and South West Europe can be seen by the reduction in nodal prices. Different price zones indicate congestion, either across borders (e.g., between France and Italy) or internally (e.g., North - South Germany).

Figure 8: Geographic representation of nodal marginal prices. Bar represents energy prices at nodal level: from $€ 10 / M W h$ in blue to $€ 100 / M W h$ in red. (NO WIND scenario above, MAX below).

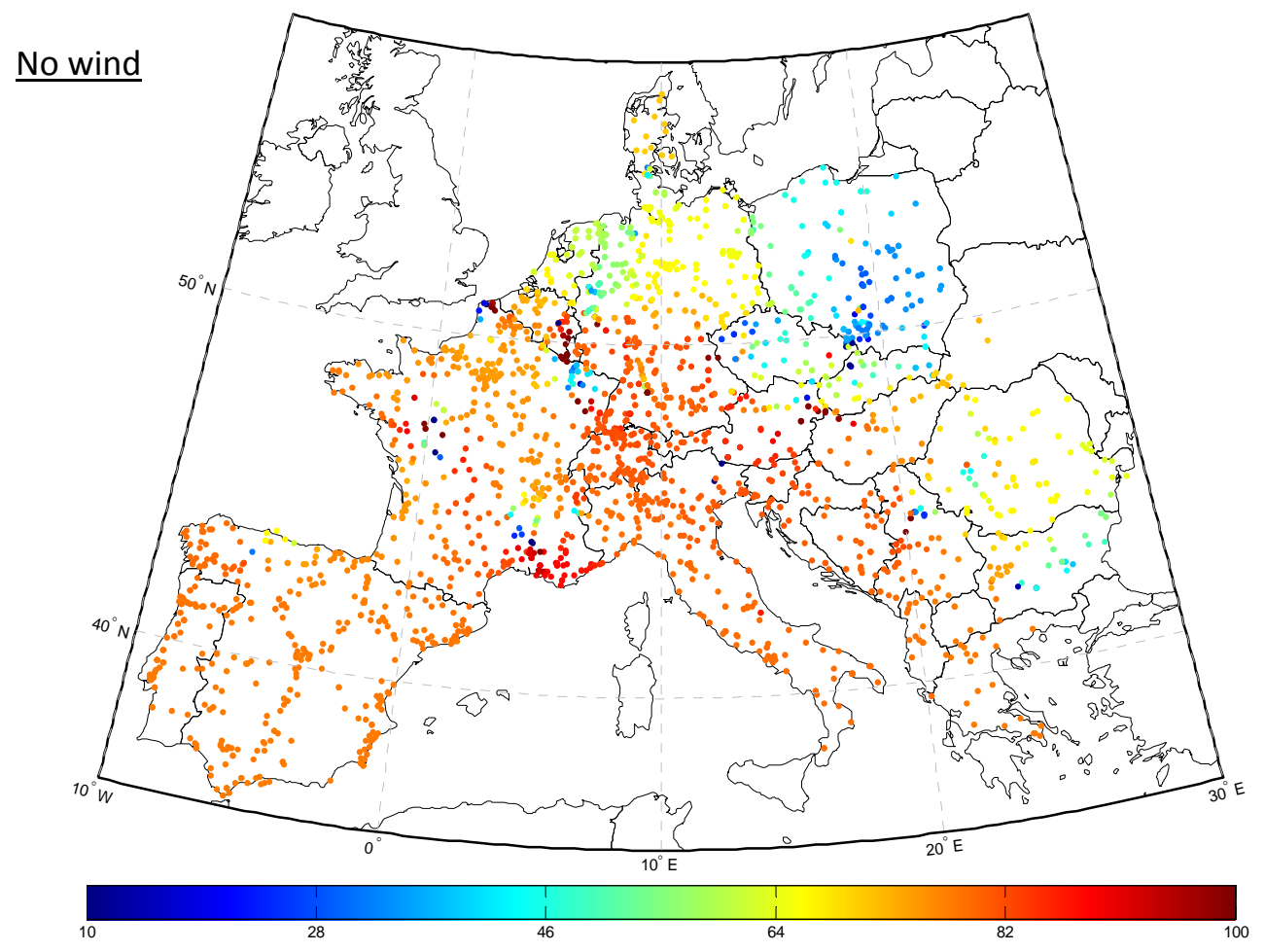




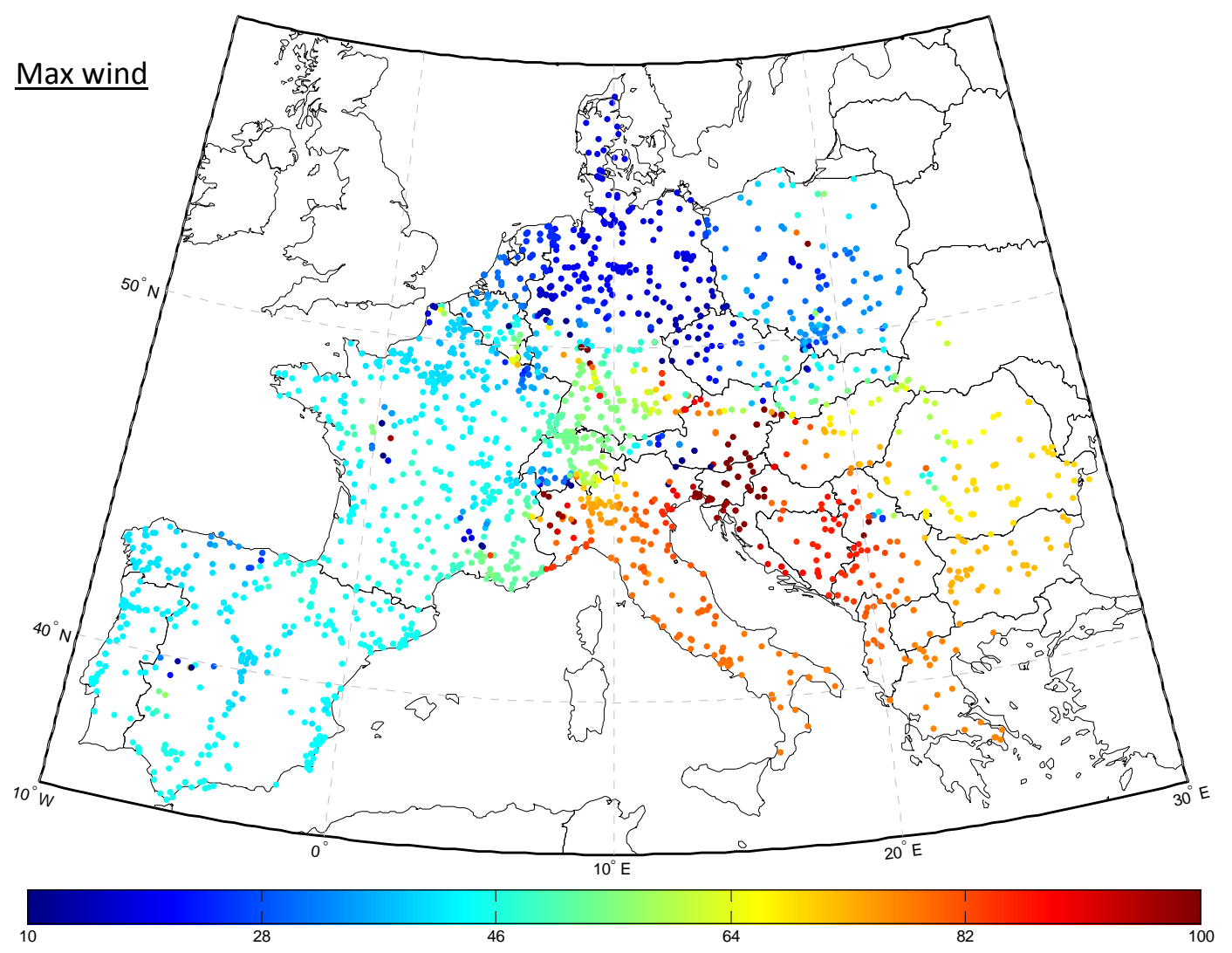

\subsection{Simulating implicit allocation of transmission capacity across Europe}

Based on the parameterization of the network representation, and after confirming that simulated nodal prices from the models provide consistent results, we then undertake the main task of the modelling exercise: the DRESDEN and MADRID models are used to calculate the TTC values for available transmission capacity between countries. Using these estimated TTC values in a TTC-constrained simulation then allows a consistent comparison with model runs under the nodal pricing regime (Section 3.3). As described in Annex A.1, the NTC (published by ENTSO-E) is calculated by the difference between TTC and TRM. The TRM is however not available for all transmission lines, thus preventing a direct comparison of modelled values and values actually announced by the TSOs.

Next, both models simulate implicit auctions allocating transmission capacity (TTCS) between European countries. The DRESDEN model undertakes a two stage approach: first, initial trading is carried out among generators and demand, respecting international transmission constraints as defined by the TTC values, but not transmission constraints within countries. This trading is based on a transhipment (path-based) model. Second, national TSOs then resolve congestion 
on lines within their respective country by redispatching national generation while keeping international net MW transfers fixed (i.e., no international redispatch). This likely yields higher operating costs than the DRESDEN nodal model (and certainly no lower costs) because the nodal model does not impose the NTC constraint, and only imposes the line constraints without restricting the international transfers to possibly suboptimal values found in the first NTC run. Meanwhile, the MADRID model simultaneously imposes the international transmission constraints (TTC values) and all line constraints, thus directly obtaining a feasible solution but underestimating the potential redispatch costs. Because this is the same as the nodal pricing simulation, except for the additional TTC constraints, the cost of the TTC run is necessarily no lower (and in all likelihood higher) than the nodal run.

Figure 9 provides the DRESDEN simulation's price results - volume weighted across EU countries - for different wind scenarios. The dashed line gives the market results from the first stage (roughly corresponding to day-ahead market). The national TSO(s) then independently pursue national redispatch to ensure the flow patterns do not violate national transmission constraints while keeping international flow patterns constant. The final energy prices thus comprise the energy prices as calculated in the first stage with an additional amount to cover redispatch costs.

Two options to translate the redispatch into redispatch costs are depicted by the grey area. For the lower end of the area it is assumed that each country's TSO can price discriminate among its nodes when redispatching, and thus limit re-dispatch costs. The upper end of the range assumes that all upward response (constrained-on production) is paid the maximum price within the country, and similarly all downward responses (constrained-off production) pays the lowest price for such buy-back within the country. Again, the TSO's net expenditures on redispatch are recovered by increasing the zonal prices. Typically the TSO has to pay the market price rather than remunerating generators at cost. The upper end of the range thus corresponds to a competitive market outcome. With market power, where generators submit bids that diverge from their variable cost, the prices could further increase. In fact, if generators anticipate payments that are available in the redispatch market, then they are likely to bid in this manner, raising prices above those depicted in the figure. 
Figure 9: EU-wide volume weighted prices from DRESDEN model. ${ }^{6}$

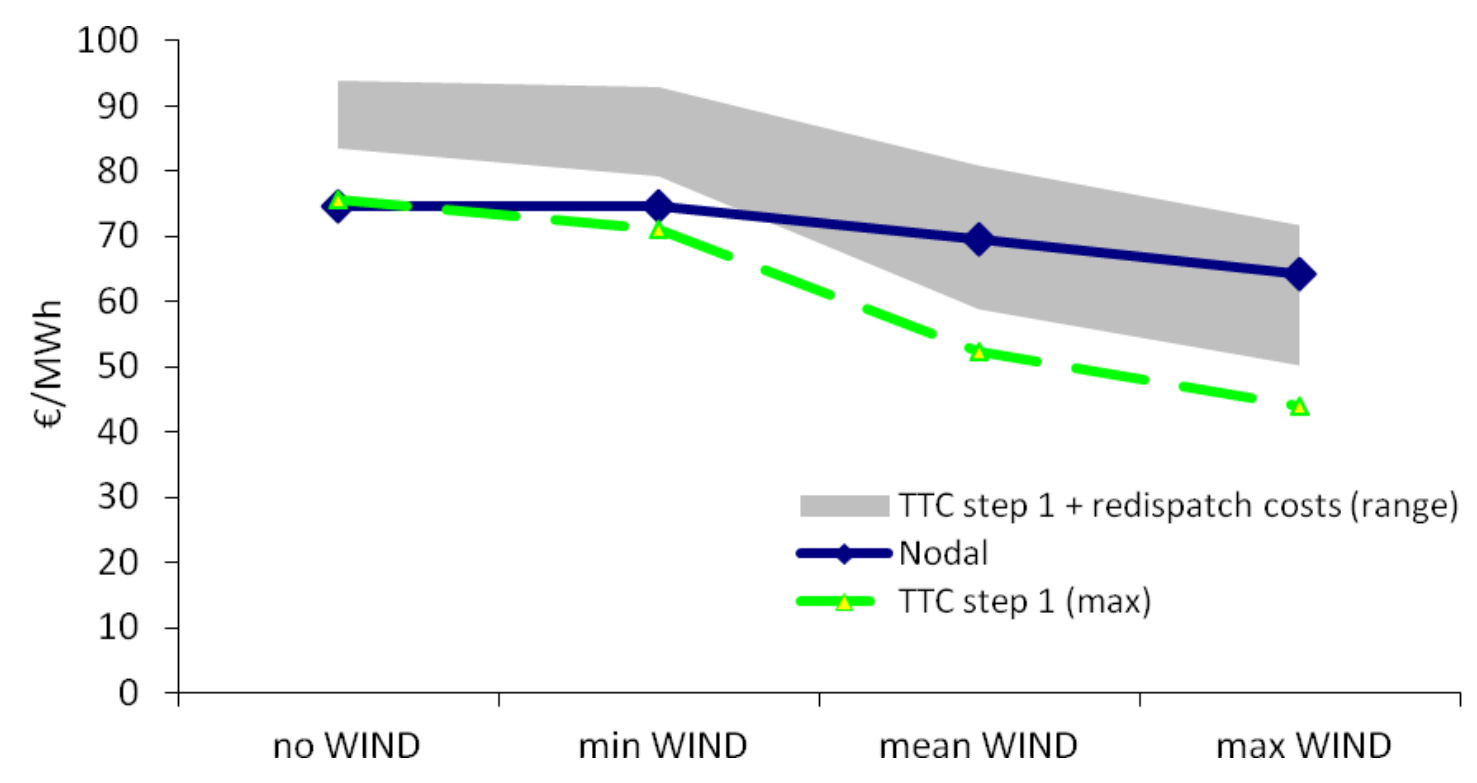

Figure 9 shows that volume weighted power prices for the day-ahead market (assuming no interaction with intraday redispatch and no strategic behaviour) are more responsive to higher wind deployment than nodal prices. The reason is that zonal pricing disregards the internal transmission constraints in the TTC structure. High wind output is free to replace - in the day ahead market at least - the most expensive generation assets without being constrained by within-country transmission limits, and reduces the market clearing price in the first stage (dayahead market).

In contrast, in the nodal market, internal constraints can prevent all of the wind output from being used. Respecting the internal transmission constraints can mean, for example, that high wind output in Germany can replace some of the coal power production in Northern Germany, but cannot replace the more expensive gas power stations in Southern Germany due to NorthSouth transmission constraints. As a result the volume weighted nodal price can remain higher than the day ahead price (excluding redispatch cost) in the TTC case.

In practice, regional prices in an NTC type approach will increase in the day-ahead market as well for the following reason. As the likelihood for redispatch increases, generators in load pockets anticipate the possible revenues in the redispatch mechanism and have incentives to increase their bids in the day-ahead market so as to not be chosen for the lower price market.

\footnotetext{
${ }^{6}$ Due to data constraints, generation and demand in Portugal and Ukraine is assumed to be fixed. Hence, these countries are not considered in the calculation of EU-wide average prices.
} 
Generators might even choose to bid strategically in the day-ahead market so as to increase the need for redispatch and costs for consumers. This strategic behaviour is known as the increasedecrease 'inc-dec' game that destroyed the PJM market when it attempted to implement something similar to zonal pricing prior to moving to nodal pricing (Hogan, 1999), and was a main contributor to the failure of the California power market in 2000-2001.

\subsection{Simulation results comparison for system costs and network utilisation}

We now compare the volume of international transfers and cost savings of the TTC and nodal flow using both the Dresden and Madrid models.

\section{International Transfers/Network Utilization}

First, we consider the level of network utilization under both congestion management regimes.

Figures $10 \& 11$ depict the total volume of international transfers that is observed in each of scenarios. The nodal pricing approach usually leads to an increase in transfers that take place between countries, up to $34 \%$ more. Thus existing network capacity is better utilized to accommodate increasingly large volumes of intermittent energy sources. The simulation results indicate that this difference is greatest in the scenario with maximum wind penetration: maximum international transfers are in the range of $42-43 \mathrm{GW}$ in both models.

The Dresden model provides the only scenario (min wind) in which nodal pricing does not increase flows. The higher volume of international flows in the NTC case results under that wind scenario because the NTC calculations assume that the French-Spanish interconnector is utilized in the direction of Spain (which allows for higher utilization as it relaxes constraints in Southern France). The example illustrates that the volume of international transfers by itself is not the target objective, as long as the transfers are not in line with a system wide power system optimization.

The simulated increase of the volume of flows resulting from nodal pricing is likely to provide a lower bound to the benefits of nodal pricing for two reasons. Firstly, the maximum possible TTC values are calculated for each pair of neighbouring countries. It is assumed that the values for all pairs are simultaneously possible, but in practice the TTC values have to be reduced to ensure that they are jointly viable. Secondly, the large redispatch volume as simulated in the DRESDEN model would create very high costs for TSOs (with wind-spilling and load-shedding assumed to be offered at $€ 500 / \mathrm{MWh}$ in that model) and ample opportunities for gaming (inc- 
dec game) - therefore in practice the TSO would issue lower TTC values to constrain international transfers and limit the level of domestic transmission constraints. This equally applies to the MADRID model; however, due to the joint representation of TTC and line constraints in a single step (rather than the two-step DRESDEN approach), the model does not explicitly calculate redispatch costs.

Figure 10 \& 11: International/cross-border energy transfers [MW] under varying levels of wind penetration for both models (MADRID results presented above, DRESDEN below).
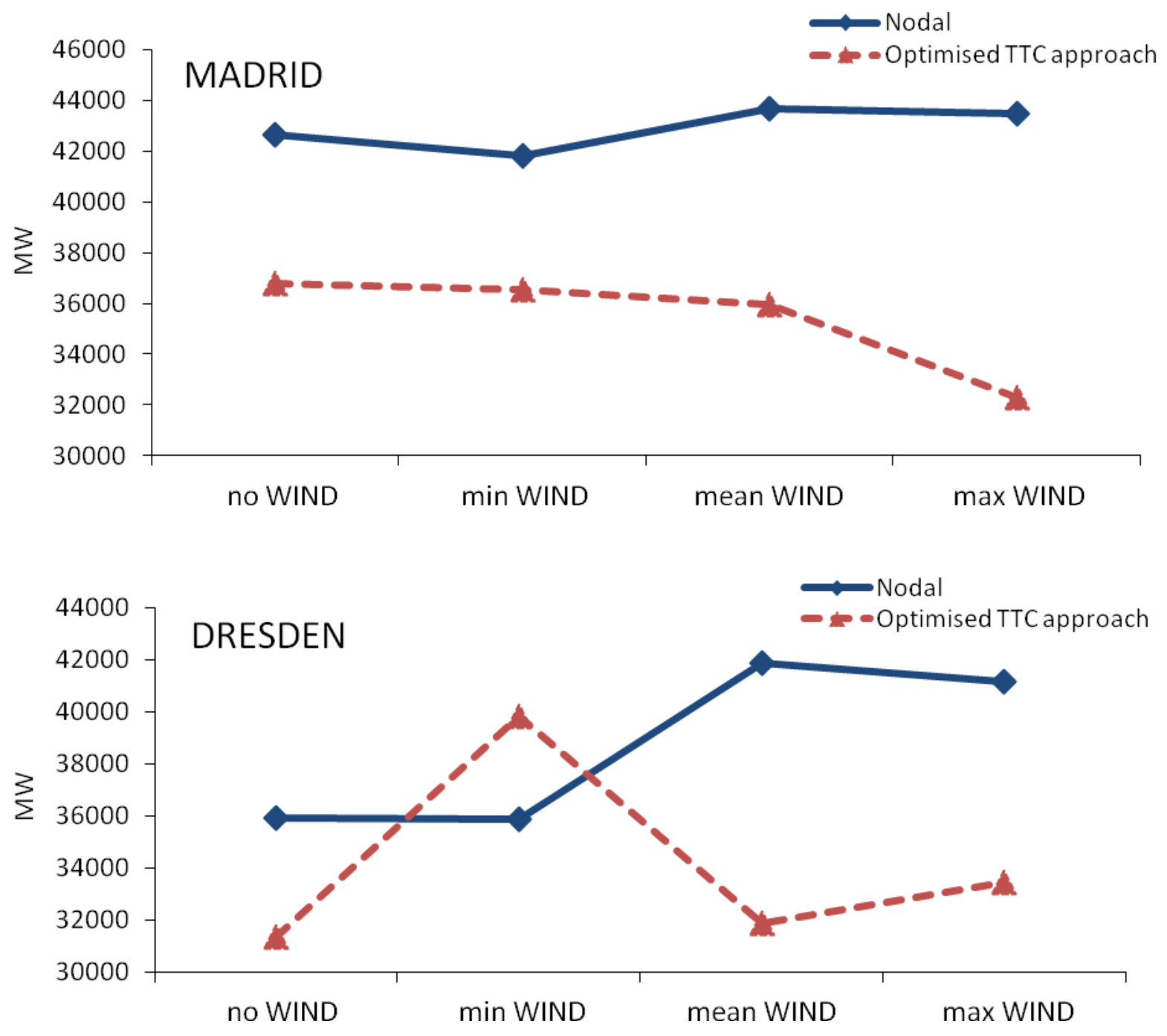

\section{Cost Savings}

Finally we were interested in the total variable costs incurred for power generation. As all demand is met across the scenarios, we summed variable generation costs (reflecting both fuel and carbon costs of generators), but ignored fixed start-up and minimum run costs. The second 
stage in the Dresden model allowed the introduction of load shedding and/or wind spilling for balancing purposes with marginal costs of this procedure arbitrarily set at $€ 500 / \mathrm{MWh}$ (greatly exceeding the marginal costs of other generation).

Figure 12: Total cost savings per hour using nodal pricing versus optimised TTC.

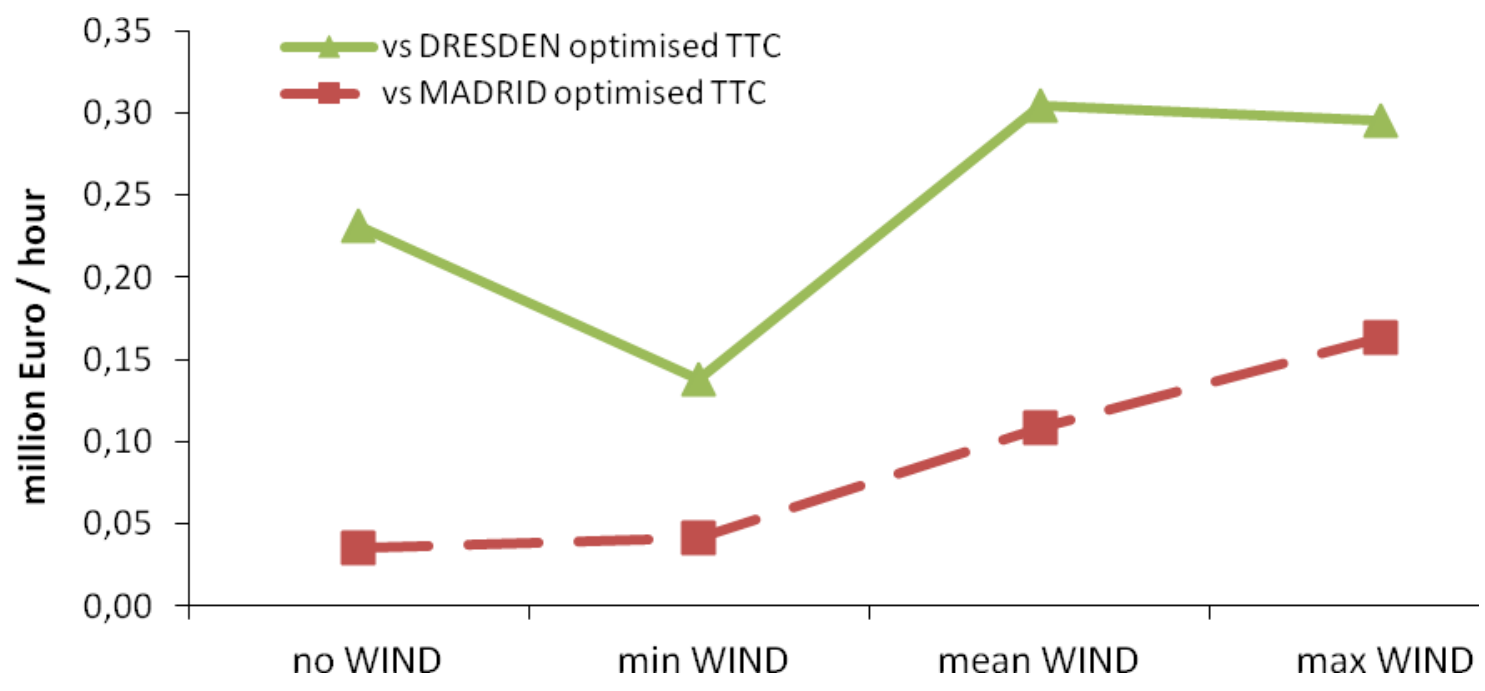

Figure 12 depicts the fuel and carbon savings that were achieved through the system wide optimization possible with nodal pricing relative to zonal pricing market designs. Multiplying these values by 8760 hours/year yields estimates of annual savings that range from $€ 0.8-€ 2.0$ billion depending on the penetration of wind power (representing $1.1 \%-3.6 \%$ of operational costs). ${ }^{7}$

\footnotetext{
${ }^{7}$ Within this calculation, we have ignored intertemporal constraints such as ramp rates. Borggrefe and Neuhoff (2010) compare the performance of zonal and nodal pricing with regard to the possibility to coordinating effective system wide intraday redispatch - and point to further benefits of nodal pricing.
} 


\section{Discussion}

Models have to abstract from many details of reality because of the lack of data or computational limitations. Thus, trade-offs are necessary when deciding upon the level of detail of the physical representation of the grid, generation and demand. In addition, the temporal dimension can be captured to different levels of detail or accuracy; from long-term investment choices to daily unit-commitment requirements or short-term representation of system flows and stability. As interconnected power systems are no longer operated according to one system-wide optimization algorithm, models could also aim to represent market design and strategic behaviour of market participants.

The focus of this paper is on the role of congestion management in the European network hence a detailed representation of the transmission grid and spatial distribution of generation and load was necessary. To allow for a comparison of two different power market designs, the main characteristics of both nodal pricing and of the implicit and joint allocation of transmission capacity had to be captured in the model. This effectively exhausted the complexity that we felt comfortable to model while retaining the ability to interpret and test the model.

The simplifications inherent in a model thus raise the question, to what extent do the qualitative and quantitative model results provide evidence for the impacts of nodal pricing on real power systems? As many of the detailed characteristics of power stations, as well as system requirements like reserve requirements, are not explicitly modelled, we focused our interpretation on the model results concerning overall congestion and pricing patterns (rather than local prices or constraint volumes of a specific line) and the comparison between two power market designs based on the same system and demand configuration. Specifically, we focused on relative price levels, difference in flow volumes, and difference in system costs. Those aggregations are likely to be more reliably projected than, for instance, prices at individual buses or flows through individual lines. For these comparisons the results of the different models are broadly consistent with each other and with observed market prices, and remaining differences can be explained by the different modelling approaches.

\subsection{Results from other studies}

It is intriguing to observe that the modelling exercise confirms observations from existing nodal pricing-based systems in the US: 
- Mansur and White (2009) studied PJM and AEP/Dayton/ComEd operations before and after their merger. Their studies show that the volume of commercial transaction between the geographical regions increased by approximately $42 \%$ after the integration of both markets. The increase is consistent without simulation results that showed up to a 34\% increase in international flows. The incremental benefit of extending nodal pricing to the AEP/Dayton/ComEd areas to PJM was $\$ 180$ million annually, which multiplied by the size ratios ( $50 \mathrm{GW}$ for the three states, $820 \mathrm{GW}$ EU) translates to a gain of $\$ 2.95$ billion. As US fuel prices in 2009 measured in USD roughly correspond to EU fuel prices in Euro, the results can be interpreted as system savings of $€ 2.95$ billion. PJM estimates that the overall benefits of integrated operation of their system are $\$ 2.2$ billion (approximately €1.8 billion) annually (Ott, 2010).

- Analysis from nodal pricing-based operations in Texas (Watson, 2011) revealed that the ERCOT system could have helped avoid potentially "millions, or hundreds of millions [USD]" if it had been implemented before a 2008 spike in power price. The system, which went fully operation December 2010, has reportedly already reduced prices by 25\%-33\% compared to December 2009 because the increased granularity of the power market design allows for more precise operations.

In addition to this experience, other simulations have quantified the benefits of nodal pricing for international coordination of dispatch. For instance, van der Weijde and Hobbs (2011) simulate both nodal and zonal power market designs on a four-node model and find that coordinated international redispatch can save up to $10 \%$ of system unit commitment and dispatch costs relative to a TTC-type market outcome. As the coordinated international redispatch - in their model - reinstates a configuration of power production that is similar to nodal pricing, the $10 \%$ savings can be interpreted as the savings of nodal pricing relative to TTCtype approach. Most of these savings are due to the ability to adjust international MW flows in balancing markets; if international rebalancing is allowed in a NTC system, then the cost savings of instead using nodal pricing are an order of magnitude smaller, but still significant.

The high value of these savings (more than three times our simulation results) relates to the higher level of congestion in the network, and the additional constraints imposed by the small number of generators in the model that can contribute to resolving the constraint. ${ }^{8}$

In another simulation study, Barth et al. (2009) obtain an estimated LMP benefit (compared to an NTC system) of $0.1 \%$ of system variable cost for the EU in the year 2015 under more than

\footnotetext{
${ }^{8}$ Note that in practice, international coordinated redispatch would incur significantly higher costs than indicated by simulation results. This is because the simulation assumed that the system operator would know marginal generation costs of all units and would be able to redispatch all units at these costs.
} 
$125 \mathrm{GW}$ of wind capacity. These benefits are a combination of improved efficiency of international transactions, within-country dispatch, and day-ahead unit commitment that considers all international network constraints instead of NTCs. However, they treat each country as a single zone with no consideration of individual circuits between countries or congestion within countries, therefore, this estimate should be viewed as a lower bound.

In other simulation studies, Oggioni and Smeers (2009) use a simple six-node network to examine the benefit of coordinated international balancing markets. Market coupling based upon nodal pricing is found to be more efficient than using NTCs. Meanwhile, Vandezande et al. (2009) provide an estimated benefit of coordinated balancing between Belgium and The Netherlands (compared to no international redispatch) to be approximately $40 \%$ of total balancing costs. ${ }^{9}$

Thus, we conclude that the empirical evidence and results from other modelling confirm that significant cost savings would likely result from a shift to nodal pricing-based congestion management on a European scale.

To the extent that initial implementation of a nodal market design will be limited to part of the EU region, only parts of these savings will be generated. However, improvements to the power market design can also offer additional savings where system-wide intraday optimization (as possible in nodal pricing related power market designs) allows for effective use of the better wind forecasts that appear during the day. Also, the benefits of transparent information on congested lines for network expansion decisions and public engagement during the planning process have not been quantified.

\subsection{EU transition to nodal pricing market design}

Clearly, shifting to a nodal power market design would require considerable changes in the institutional settings in Europe. The current separation of power exchanges and grid operation would have to be abandoned in favour of an integrated ISO (Independent System Operator) or closely coordinated ISOs, at least for the day-ahead and intraday market. Future and other

\footnotetext{
${ }^{9}$ Other studies have examined the benefits of LMP, but not specifically relative to NTC-based management of intercountry constraints. Green (2007) estimates that LMP would provide efficiency benefits equal to about $1.5 \%$ of generator revenues in the UK due to better dispatch and demand response to prices. Leuthold et al. (2005) estimate that LMP would provide a $0.6-1.3 \%$ increase in economic surplus in the German power markets. A further $1 \%$ gain would result if more wind capacity is built because of increased congestion. Weigt (2006) extends that model to include unit commitment of aggregations of power plants and international transmission. He obtains a benefit equal to $0.06 \%$ of the market surplus for all of Europe, including a net $0.79 \%$ increase in consumer surplus which is partially offset by decreases in profits.
} 
derivative markets can be handled by one or several institutions distinct from the system and spot market operator; nevertheless, such institutional changes raise several objections even beyond the evident self-interests of some of the current players in the markets. Four major concerns may be identified:

- Feasibility. The entire European system is larger $(600+\mathrm{GW})$ than the PJM area (160+ $\mathrm{GW})$, therefore the algorithms for optimal commitment and dispatch will require more computation time. This clearly has to be checked carefully, but the improvements in computer and algorithm performance have been tremendous over the last decade, and further improvements are expected to come. Thus, the importance of this constraint is likely to fade away over time; even if it is possibly relevant today at a full European scale, it is certainly not relevant for an implementation in a limited number of European states in the next years.

- Security. Today accountability for system security in Europe rests on the shoulders of the control zone operators (TSOs) at a decentralized level. Shifting this responsibility to a more central level is feared by some to reduce system security. Although this argument sounds convincing at first sight, there are also counter-arguments. The PJM experience shows that centralized operation does not mean increased unreliability, e.g., the territory covered by PJM was saved from the large scale August 2003 blackout across the northeast USA and some Canadian provinces because an integrated real time dispatch algorithm provided timely and accurate information that allowed for quick responses. A coordination of real-time responses to disturbance may hence even contribute to increased system security. Alternatively, it is possible to maintain the realtime operation and security responsibility at a decentralized level even with centralized day-ahead and intraday dispatch. The shift in responsibility would then occur at gate closure (e.g., 1-2 hours from real time). This would obviously raise several coordination issues, but these would be of a technical nature and could be solved, see Baldick et al. (1999) and Aguado and Quintana (2001).

- Market Liquidity. The argument here is that large areas with uniform prices encompass multiple agents, thus inducing more liquid markets. In turn, this creates more hedging possibilities, helping in particular smaller power plant operators. This issue certainly requires further investigation, yet the financial hedging using derivatives may still be concentrated on one reference product (like Brent or WTI in the oil market). This reference product may correspond to some particular node in the system (like Henry Hub for US gas contracts), or it may be a virtual system point or system average (like the Nordel system marginal price). Locational deviations from this reference price, as far as they are temporary and stochastic, will largely level out over a month or year and thus do not constitute a major risk for the individual plant operator. If the deviations by 
- Lack of institutional competition. Ockenfels et al. (2008) argue that the centralization of operation decisions eliminates the competition between different trading institutions (e.g., power exchanges vs. OTC trading). Also the competition between different power plant operation strategies characteristic for today's bilateral and voluntary trading arrangements is at first sight replaced by one centralized dispatch algorithm. However, in the US organized markets, independent power exchanges coexist with the formal ISO markets, and there are multiple trading institutions that deal in forward products. Obviously in this dispatch algorithm, power plant owners still may influence the operation of their power plants through the bids which they submit to the system operator, or they can self-schedule, accepting whatever prices the market offers. A delicate issue certainly is to what extent cost-based bids will be required by the ISO: PJM and the California ISO, for instance, require them as a back-up to be used in the case congestion creates opportunities for exercising local market power (O'Neill et al., 2008).

These and other issues certainly have to be discussed in detail when it comes to implementing nodal pricing in practice. Yet the analysis presented here at least provides a clear economic rationale for moving further ahead in this direction.

\section{Conclusion}

An important issue for large scale renewable energy integration within Europe is the more efficient use of and development of additional network capacities, and managing congestion problems.

This paper sets out to explore whether the choice of the design of EU spot power markets makes a difference for the effective integration of renewables. Two market designs are compared across Europe: (i) an optimized approach of implicit auctions of transmission capacity between nationally defined price zones; and (ii) a nodal pricing approach.

The analysis has some limitations. In particular, the quality of the available data has some problems, and is certainly insufficient to allow for the evaluation of individual lines or investment projects. However, for the aggregate analysis presented here, the data is adequate, and is of better quality than that used in any previously published EU-wide analysis of this issue. 
Additionally, specific operation constraints, e.g., for system security considerations, are omitted since generally these are not formally implemented or published by European TSOs but instead are carried out informally by the operators based on established practices.

Simulating nodal prices with the data set provides a second set of insights that confirms previous studies. Most of the transmission constraints are not associated with lines between countries, but with lines within countries. The current European power market design (outside of Scandinavia) does not make this explicit. This creates incentives for system operators to limit international flows to avoid domestic congestion that requires redispatching of power stations within their boundaries to resolve remaining constraints. Furthermore, the nodal pricing simulations illustrate that the congestion - and price - patterns vary considerably between wind scenarios. This suggests that approaches that aim to define price zones within countries are not suitable to address internal congestion, as the zones would either have to vary depending on system conditions (impractical for contracting purposes), or be small (and thus be essentially equivalent to nodal pricing).

Finally, the two models (MADRID and DRESDEN) are used to calculate TTC values for limits to commercial transfers between countries. As no formal standardized method exists for TTC calculations, and national TSOs do not report on their specific methodology, we explore a range of methodologies that capture some of the variations that might be inherent in current TTC calculations. These TTC values are then used as a basis for modelling the single price zones according to national boundaries with one implicit auction for all international transmission capacity. The comparison with the nodal pricing results suggests that some $€ 0.8$ - $€ 2.0$ billion cost savings per year and an increased use of international transmission capacity by up to $34 \%$ is possible with nodal pricing. These results are broadly consistent with empirical values from the USA and other simulation models.

Based on these results, further research should address the issue whether the resulting efficiency improvements and increased transparency justifies the cost of implementing new systems, and whether the political effort necessary to change the current design is achievable. 


\section{References}

\section{Aguado \& Quintana (2001)}

Aguado, J. A. \& Quintana, V. H., (2001): “Inter-utilities power-exchange coordination: a marketoriented approach", IEEE Transactions on Power Systems 16 (3): pp. 513-519, 2001.

\section{Androcec \& Wangensteen (2006)}

Androcec, I. \& Wangensteen, I. (2006): “Different Methods for Congestion Management and Risk Management", 9th International Conference on Probabilistic Methods Applied to Power Systems, KTH, Stockholm, Sweden - June 11-15, 2006.

\section{Baldick et al. (1999)}

Baldick, R., Kim, B. H., Chase, C. \& Luo, Y., (1999): “A Fast Distributed Implementation of Optimal Power Flow", IEEE Transactions on Power Systems 14 (3): pp.858-864, 1999.

\section{Barth et al. (2009)}

Barth, R., Apfelbeck, J., Vogel, P., Meibom, P. \& Weber, C. (2009): “Load-flow based market coupling with large-scale wind power in Europe", In: Proceedings of the 8th International Workshop on Large Scale Integration of Wind Power into Power Systems as well as on Transmission Networks for Offshore Wind Farms. 14-15 October 2009, Energynautics Bremen 2009.

\section{Bialek (2005)}

Bialek, J. W. (2005): "Blackouts in the US/Canada and continental Europe in 2003: is liberalisation to blame?", IEEE PowerTech Conference, St. Petersburg, 2005.

\section{Bialek (2007)}

Bialek, J. W. (2007): "Why has it happened again? Comparison between the 2006 UCTE blackout and the blackouts of 2003", IEEE PowerTech Conference, Lausanne, 2007.

\section{Borggrefe \& Neuhoff (2010)}

Borggrefe, F. \& Neuhoff, K. (2010): “Balancing and Intraday Market Design - Options for Wind Integration", Climate Policy Initiative working paper, September 2010.

\section{Brunekreeft et al. (2005)}

Brunekreeft, G., Neuhoff, K. \& Newbery, D. (2005):“Electricity transmission: An overview of the current debate", Utilities Policy 13(2), 73-94, June 2005. 


\section{Ehrenmann \& Smeers (2005)}

Ehrenmann, A. \& Smeers, Y. (2005): "Inefficiencies in European Congestion Management Proposals", Utilities Policy13 (2):135-152.

\section{EC (2003)}

European Commission (EC) (2003): “Commission Staff Working Paper: Second benchmarking report on the implementation of the internal electricity and gas market - Annex E: Congestion Management in the EU Electricity Transmission Networkp.74", April 2003.

\section{EnBW}

EnBW Transportnetze AG: “Allgemeines Modell zur Berechnung der Gesamtübertragungskapazität und der Sicherheitsmarge der EnBW Transportnetze AG" (in German), accessible http://www.enbw.com/content/de/netznutzer/media/pdf/Allgemeines_Kapazit_tsberechnun gsmodell.pdf, 2010.

\section{ENTSO-E (2010)}

European Network of Transmission System Operators for Electricity (ENTSO-E) (2010): "System Operations Committee Regional Group Nordic - Principles for determining the transfer capacities in the Nordic power market", June 2010.

\section{ERGEG (2010)}

European Regulators' Group for Electricity and Gas (ERGEG) (2010): “Draft Framework Guidelines on Capacity Allocation and Congestion Management", Ref: E10-ENM-20-03, September 2010.

\section{ETSO (2001a)}

European Transmission System Operators (ETSO) (2001a): "Definitions of Transfer Capacities in Liberalised Electricity Markets - Final Report", April 2001.

\section{ETSO (2001b)}

ETSO (2001b): "Procedures for cross-border transmission capacity assessments", October 2001.

\section{ETSO (2007)}

ETSO (2007): “Regional Flow-Based Allocations - State-of-Play. European Transmission System Operators", accessible http://www.entsoe.eu/_library/publications/etso/ETSO\%20_flowbased\%20allocation_final12Mar2007.pdf, 2007. 
EWIS (2010)

European Wind Integration Study, EWIS (2010). Accessible http://www.wind-integration.eu, March 2010.

Fingrid (2009)

Fingrid (2009):“Determining the transmission capacity”, October 2009.

\section{Green (2007)}

Green, R. (2007): "Nodal Pricing of Electricity: How Much Does it Cost to Get it Wrong?", Journal of Regulatory Economics 31 (2): 125-149.

\section{Hogan (1999)}

Hogan, W. (1999): "Restructuring the Electricity Market: Institutions for Network Systems," Harvard University, April 1999.

\section{Hogan (1992)}

Hogan, W. (1992): "Contract Networks for Electric Power Transmission", Journal of Regulatory Economics 4(3): 211-242.

\section{Leuthold et al. (2005)}

Leuthold, F., Rumiantseva, I., Weigt, H., Jeske, T. \& Hirschhausen, C. von (2005): “Nodal Pricing in the German Electricity Sector - A Welfare Economics Analysis, with Particular Reference to Implementing Offshore Wind Capacities", Working Paper WP-EM-08a, Dresden University of Technology, Chair for Energy Economics and Public Sector Management, accessible http://www.tudresden.de/wwbwleeg/publications/wp_em_08a_leuthold_rumiantseva_weigt_et\%20al_nodal _\%20pricing_germany.pdf, 2005.

\section{Leuthold (2006)}

Leuthold, F. (2006): “Flow-Based Coordinated Explicit Auctions: Revenue Distribution Analysis and Developments in Applied European Congestion Management", Diploma Thesis, Dresden University of Technology, Chair for Energy Economics and Public Sector Management, accessible http://www.tudresden.de/wwbwleeg/mitarbeiterseiten/fl/leuthold_2006_coordinated_auction_revenue_dist ribution.pdf, 2006. 


\section{Leuthold et al. (2008)}

Leuthold, F., Weigt, H. \& Hirschhausen, C. von (2008):"Efficient pricing for European electricity networks - The theory of nodal pricing applied to feeding-in wind in Germany", Utilities Policy 16:284-291, 2008.

\section{Mansur \& White (2009)}

Mansur, E. T. \& White, M. W. (2009): "Market organization and efficiency in electricity markets", accessible http://bpp.wharton.upenn.edu/mawhite/, 2009.

\section{MAT09 (2009)}

MAT09 - Zimmerman, R.D., Murillo-Sánchez, C. E. \& Thomas, R. J. (MAT09): “MATPOWER's Extensible Optimal Power Flow Architecture", Power and Energy Society General Meeting, IEEE, pp.1-7, July 26-30, 2009.

\section{Ockenfels et al. (2008)}

Ockenfels, A., Grimm, V. \& Zoettl, G. (2008): "Strommarktdesign. Preisbildungsmechanismus im Auktionsverfahren für Stromstundenkontrakte an der EEX“, accessible (in German) http://ockenfels.uni-koeln.de/uploads/tx_ockmedia/Gutachten_EEX_Ockenfels.pdf, May 2008.

\section{Oggioni \& Smeers (2009)}

Oggioni, G., \& Smeers, Y. (2009): “Degree of coordination in market-coupling and countertrading",. CORE Discussion Paper 2010001, Catholic University of Louvain, Louvain-la-Neuve, Belgium.

\section{O’Neill et al. (2005)}

O’Neill, R. P., Sotkiewicz, P. M., Hobbs, B. F., Rothkopf, M. H. \& Stewart, W. R. Jr. (2005): "Efficient Market-Clearing Prices in Markets with Nonconvexities," Euro. J. Operational Research, 164(1), July 1, 2005, 269-285.

\section{O’Neill et al. (2008)}

O’Neill, R. P., Helman, U., Hobbs, B. F. \& Baldick, R. (2006): “Independent system operators in the United States: History, lessons learned, and prospects," Ch. 14, in F. Sioshansi and W. Pfaffenberger, Electricity Market Reform: An International Perspective, Global Energy Policy and Economics Series, Elsevier, 2006, pp. 479-528. 


\section{Ott (2010)}

Ott, A. (2010): “PJM - LMP Market Overview”, Presented at CPI/Re-shaping workshop in Brussels, accessible www.climatepolicyinitiative.org/AndyOtt_PJMDOCS-588255-v2-Brussels__PJM_Market.pdf, June 2010.

\section{PSE (2010)}

PSE Operator S.A. (2010): Personal communication with Pawel Rodo, Senior System Engineer, March 2010.

\section{RWE (2010)}

RWE Transportnetz Strom GmbH: “Berechnung von regelblocküberschreitenden Übertragungskapazitäten zu internationalen Partnernetzen," accessible http://www.amprion.net/sites/default/files/pdf/Genehmigtes\%20Kapazitaetsmodell.pdf (in German - accessed December 2010).

\section{Schweppe et al. (1988)}

Schweppe, F. C., Caramanis, M. C., Tabors, R. D. \& Bohn, R. E. (1988): “Spot Pricing of Electricity", Boston, Kluwer Academic Publishers, 1988.

\section{TradeWind (2009)}

TradeWind (2009) - Van Hulle, F.,Tande, J. O., Uhlen, K., Warland, L., Korpås, M., Meibom, P.,Sørensen, P., Morthorst, P. E., Cutululis, N., Larsen, H., Woyte, A., Verheij, F., Kleinschmidt, C., Moldovan, N., Holttinen, H.,Lemström, B.,UskiJoutsenvuo, S., Gardner, P.,Purchala, K., Tiedemann, A. \& Kreutzkamp, P.: "Tradewind - Final Report", TradeWind, accessible http://www.trade-wind.eu, February 2009.

\section{Transpower (2009)}

Transpower Stromübertragungs GmbH (2009): “Determination of Transfer Capacity at Auctioned transpower Cross-Border Transfer Points", accessible http://www.transpower.de/pages/tennettso_en/Transparency/Publications/Congestion_mana gement/Overview/description_congestion_management_en.pdf, February 2009.

\section{UCTE (2004)}

Union for the Co-ordination of Transmission of Electricity (UCTE) (2004): “UCTE Operation Handbook".

\section{Van der Weijde \& Hobbs (2011)}


Van der Weijde, A. D. Hobbs, B.F. (2011): "Locational-based Coupling of Electricity Markets: Benefits from Coordinating Unit Commitment and Balancing Markets", Journal of Regulatory Economics 39 (3), pp 223-251

\section{Vandezande et al. (2009)}

Vandezande, L., Saguan, M., Meeus, L., Glachant, J. -M., \& Belmans, R. (2009). Assessment of the implementation of cross-border balancing trade between Belgium and The Netherlands. Proceedings, 6th International Conference on the European Energy Market, Leuven.

\section{Vattenfall (2010)}

Vattenfall Europe Transmission GmbH, "Allgemeines Modell der Vattenfall Europe Transmission GmbH für die Berechnung der Gesamtübertragungskapazität und der Sicherheitsmarge," accessible http://www.50hertztransmission.net/cps/rde/xbcr/trm_de/allgemeinesmodellvet_54436.pdf (in German accessed December 2010).

\section{Vujasinovic et al. (2005)}

Vujasinovic, Z. Z., Apostolovic, M. R., Mijailovic, S. V. (2005): “Development of Congestion Management Procedures in South-East Europe", Electricity Coordinating Center, Belgrade, accessible http://www.ekc-Itd.com/files/radovi/Vujasinovic-Apostolovic-Mijailovic_BPC2005.pdf\#search=\%22EKC\%20congestion\%20management\%20methods\%22.

\section{Watson (2011)}

Watson, M. (2011): “Platts: Megawatt Daily - Nodal prices could have eased spike: Texas regulator", McGraw Hill, Edition: January 2011.

\section{Weigt (2006)}

Weigt, H. (2006): “A Time-Variant Welfare Economic Analysis of a Nodal Pricing Mechanism in Germany", Working Paper WP-EM-11, Dresden University of Technology, Chair for Energy Economics and Public Sector Management, 2006.

\section{Wood \& Wollenberg (1996)}

Wood, A., J. \& Wollenberg, B. F. (1996): "Power generation operation and control”, Wiley Interscience, 1996. 


\section{Zhou \& Bialek (2005)}

Zhou, Q. \& Bialek, J. W. (2005): “Approximate Model of European Inter-connected System as a Benchmark System to Study Effects of Cross-Border Trades", IEEE Transactions on Power Systems 20(2), May 2005. 


\section{ANNEX}

\section{A Methodologies: TTC Calculation and the two Models for Nodal Prices}

\section{A.1 Survey of TTC methodologies}

International capacity allocations distinguish between commercial transfer limits (which are used by market participants to plan their cross-border trades), and physical values (as used by system operators in real-time operation (ETSO, 2001a)). The following descriptions refer to the former, i.e. the determination of limits on commercial exchange programs; direct quotations from ETSO's guidelines are indicated by italics.

Total Transfer Capacity (TTC) is the maximum exchange program between two areas compatible with operational security standards applicable at each system if future network conditions, generation and load patterns were perfectly known in advance.

The computation of TTC starts with establishing a Base Case Exchange (BCE), based on the best available information on network conditions, generation and load patterns, and planned crossborder transactions. To compute the TTC from area A to area $B$, generation is increased stepwise in area $A$ and decreased in area $B$, maintaining loads the same, until security limits in either system A or B are reached:

$T T C=B C E+\triangle E$

where $\Delta \mathrm{E}$ is the maximum increase in transfer before security limits are breached.

An additional security margin, the Transmission Reliability Margin (TRM), is imposed to account for uncertainties arising from the functioning of frequency regulation, emergency exchanges, and inaccuracies in data and measurements.

The TRM is determined by each TSO in order to guarantee the operation security of its own power system. In other words, the TRM translates the somewhat abstract representation of transfers contained in the TTC determination into limits on scheduled commercial transfers that result in manageable physical transfers in real time. 
Net Transfer Capacity (NTC) is the maximum exchange program between two areas compatible with security standards applicable in both areas and taking into account the technical uncertainties on future network conditions. It is defined as:

$N T C=T T C-T R M$

The TTC, TRM and NTC values for a given pair of areas can be different for transfers in opposite directions. ENTSO-E publishes a table of "Indicative values for NTCs in Europe" on its website twice a year.

Operationally, there are three allowed options for modelling the transfer of generation between areas in TTC calculations (UCTE, 2004):

- Method A: Each chosen injection is scaled in proportion to the remaining available capacity at the relevant generator node. The value of $\triangle E \max$ (i.e., TTC-BCE) is determined when either all generators reach their maximum outputs, or if a network operational ( $\mathrm{N}-1$ security) limit is reached. This method brings the key advantage that physical generator output limits are respected. The UCTE Handbook states that it should therefore be used under normal circumstances.

- Method B: If the necessary data on generation limits for the first method are not available, the generator outputs may be scaled without consideration of output limits.

- Method C: The generator outputs are modified according to merit order, with limits on output being respected.

In this study MADRID and DRESDEN models are both based on "Method C." As described in the next section, MADRID's model can be interpreted as more conservative than DRESDEN with respect to system generation costs.

As mentioned above, detailed information is available on methods for TTC calculation. However, NTC determination is more difficult, as the public information on methods used for determining TRMs is limited. ETSO (2001b) suggests that the margin required for loadfrequency control can be determined by statistical analysis of historical time series, and that the margins required for reserve sharing and emergency transfers should be agreed upon between operators. It also discusses how these components of the TRM should be combined. However, the precise calculations are not described in that source, and cannot be duplicated based on that information. 
Operational experience from three control areas illustrates the differences in the methods that different TSOs use to determine TRMs. This diversity of methods prevents a comparison of modelled and actually announced values by the TSOs, as discussed in Section 3.4:

- For Nordpool, ENTSO-E (2010) states that in practice, the TRMs between areas in Nordpool are based on transfers due to frequency regulation only. It gives the current TRM values used as $100 \mathrm{MW}$ between Sweden and Finland, $150 \mathrm{MW}$ between Sweden and southeastern Norway, and $50 \mathrm{MW}$ for most of the remaining connections. A further description for the specific case of Finland is given in Fingrid (2009).

- To determine the TRM, a number of the German TSOs (EnBW, VE Transmission, RWE, Transport 2009) use a heuristic formula. They multiply the square root of the number of connection circuits between control zones with $100 \mathrm{MW}$ to obtain the TRM. Some examples of the numbers of cross-border circuits are 4 (Germany to France), 6 (Germany to Netherlands), 15 (Germany to Switzerland), and 12 (Germany to Austria).

- Information supplied directly to us by the Polish System Operator (PSE Operator S.A.) confirms that there are no universal regulations defining the TRM determination process; the TRM is said to be lower for shorter time horizons, when uncertainty is reduced.

\section{A.2 Nodal Pricing Model}

We now describe the methodologies that we use to calculate nodal pricing, in this section, and TTC. We used the Ecofys, Madrid, and Dresden models to calculate the nodal dispatch across the EU. The nodal pricing model determines the cost minimizing dispatch $\mathbf{g}$ of power plants respecting economic and technical restrictions, namely energy balance, line capacity limitations, and minimum and maximum generation capacity limits.

The energy balance ensures the balance of demand $\mathbf{d}_{\mathbf{0}}$, generation of thermal power plants $\mathbf{g}$, renewable wind generation $\mathbf{w}$, and nodal injections or withdrawals from the network $\mathbf{B} \boldsymbol{\theta}$ (i.e., a linearized load flow that expresses transmission flows as a linear function of voltage angles). To allow for the possibility of wind spillage, wind generation $\mathbf{w}$ is variable and bounded by the available wind generation $\mathbf{w}_{\mathbf{0}}$.

Thermal power generation is restricted by their minimum generation requirement $\mathbf{g}^{-}$and the maximum available capacity $\mathbf{g}^{+}$. To incorporate minimum generation constraints, a binary status 
variable $\mathbf{u}$ is introduced, indicating the operating status of a power plant. In a unit commitment model, $\mathbf{u}$ is a decision variable; in a dispatch model, it is predetermined.

The power flow and resulting nodal injection or withdrawal are based on DC load flow equations (e.g., Schweppe et al., 1988) and restricted by maximum thermal transmission capacity $\mathrm{f}^{+}$. Transmission losses are neglected. Locational marginal prices are defined as the dual variable of the energy balance. The final mixed integer linear program for the unit commitment problem is shown in (1).

$$
\begin{array}{ll}
\min & \mathbf{m c}{ }^{T} \cdot \mathbf{g} \\
\mathrm{s} . \mathrm{t} . & \mathbf{B} \cdot \boldsymbol{\theta}-\mathbf{g}+\mathbf{d}_{0}-\mathbf{w}=0 \\
& -\mathbf{f}^{+} \leq \mathbf{H} \cdot \boldsymbol{\theta} \leq \mathbf{f}^{+} \\
& \mathbf{u} \cdot \mathbf{g}^{-} \leq \mathbf{g} \leq \mathbf{u} \cdot \mathbf{g}^{+} \\
& \mathbf{0} \leq \mathbf{w} \leq \mathbf{w}_{0}
\end{array}
$$

where:

mc: Marginal costs

g: Bus power generation

B : Nodal susceptance matrix

$\boldsymbol{\theta}$ : $\quad$ Bus angles vector

$\mathbf{d}_{\mathbf{0}}$ : Initial bus power demand

w: Bus wind generation

$\mathbf{w}_{\mathbf{0}}$ : Available bus wind generation

H : $\quad$ Branch susceptance matrix

$\mathbf{f}^{+}$: $\quad$ Branches maximum power flow

u: $\quad$ Binary power plant status variable $\{0,1\}$

$\mathbf{g}^{-}$: $\quad$ Minimum capacity of generation units

$\mathbf{g}^{+}$: Maximum capacity of generation units.

We apply more than one variant of the above nodal pricing model. The ECOFYS and MADRID models assume that all power plants in the system to be online. Thus vector $\mathbf{u}$ is fixed to one and power plants have to produce within their minimum and maximum capacities.

Consequently, the problem reduces to a linear program with a fixed unit commitment. On the other hand, the DRESDEN model optimizes the unit commitment of power plants and the power plant dispatch simultaneously treating $\mathbf{u}$ as a variable. Hence, results of different nodal pricing models can be interpreted as more conservative (in the case of MADRID and ECOFYS) 
and more optimistic estimates (in the case of DRESDEN) with respect to system generation costs, since DRESDEN provides more flexibility.

Given this formulation of the nodal pricing model, both MADRID and DRESDEN compute total transfer capacities (TTC). Simulations are made following a two-step method. First, TTC values are computed. Second, using this computed TTC, system dispatch is simulated under different assumptions to calculate resulting international flows.

\section{A.3 Calculation of the TTC capacity in the MADRID model}

Several possible ways exist for computing the total transfer capacity (TTC) between neighbouring countries. The following method can be viewed as an implementation of "Method $C^{\prime \prime}$ from Section A.1 above as generation is determined endogenously. Demand in country A is incremented exogenously in an iterative fashion, whereas generation in country $B$ is increased endogenously in response to serve the additional demand until physical limits (either transmission limits or generation bounds) are reached.

$\max \lambda$

$$
\begin{array}{ll}
\text { s.t. } & \mathbf{B} \cdot \boldsymbol{\theta}-\mathbf{g}+\left(\mathbf{d}_{0}+\lambda \cdot \mathbf{d}_{\lambda}\right)=0 \\
& -\mathbf{f}^{+} \leq \mathbf{H} \cdot \boldsymbol{\theta} \leq \mathbf{f}^{+} \\
& \mathbf{g}^{-} \leq \mathbf{g} \leq \mathbf{g}^{+}
\end{array}
$$

where:

$\lambda$ : $\quad$ Transfer capability parameterization factor

$\mathbf{d}_{\lambda}$ : $\quad$ Bus power demand evolution vector.

Mathematically, TTCs are computed by maximizing the additional demand $\mathbf{d}$ in country $\mathrm{A}$ which can be served by additional generation $\mathbf{g}$ in country $\mathrm{B}$. The bus power demand evolution vector $\mathbf{d}$ is proportional to the demand in country $A$. Only generators in country $B$ are included in vector $\mathbf{g}$ whereas for the rest of the system, generation is a fixed power injection. The optimization is performed for each pair of neighbouring countries. The TTC value is given by adding the total demand increment d (i.e., the sum of its components). Generation cost values are not considered when computing the TTC by this method.

There are two different methods to model how TTC values could be used by TSOs in order to constrain international exchanges. In the first method, it is assumed that TSOs in countries A 
and B constrain the physical flow across the border to the TTC value. The associated linear program is:

$\min \mathbf{m} \mathbf{c}^{T} \cdot \mathbf{g}$

s.t. $\mathbf{B} \cdot \boldsymbol{\theta}-\mathbf{g}+\mathbf{d}_{0}-\mathbf{w}=0$

$-\mathbf{f}^{+} \leq \mathbf{H} \cdot \boldsymbol{\theta} \leq \mathbf{f}^{+}$

$$
\begin{aligned}
& \mathbf{g}^{-} \leq \mathbf{g} \leq \mathbf{g}^{+} \\
& \mathbf{0} \leq \mathbf{w} \leq \mathbf{w}_{0} \\
& -T T C_{B \rightarrow A} \leq \mathbf{e}_{A \rightarrow B}^{T} \cdot \mathbf{H} \cdot \boldsymbol{\theta} \leq T T C_{A \rightarrow B} \forall A, B
\end{aligned}
$$

where the new notation is:

$T T C_{\mathrm{A}->\mathrm{B}}$ : $\quad$ TTC value from country $\mathrm{A}$ to $\mathrm{B}$

$\mathbf{e}_{A \rightarrow B}$ : Vector to select border branches between countries $A$ and $B$. Its components are +1 if the branch crosses from $A$ to $B,-1$ if it crosses from $B$ to $A$ and 0 otherwise.

The second model instead assumes that TTC values are used in order to constrain the interchanges by setting bounds of the flows between countries. A notional transmission network is assumed consisting of the different countries as nodes. The flows across the branches in the notional network joining the different countries are bounded by the TTC values (see Figure i below). The notional network is a pure transhipment (or path-based) network, i.e., no second (voltage) Kirchhoff law is enforced on it. However, the model considers a fixed split between direct and indirect exports from one country to another; for instance, that energy exports from country $A$ and $B$ are partially direct transfers from $A$ to $B$, and partially indirect transfers through $\mathrm{C}$. In that respect, it models the underlying reality more accurately than a pure transhipment network. If the second Kirchhoff law were also considered, the presently preferred Load Flow Based Allocation approach would be obtained.

The associated mathematical program is:

Figure i: Mathematical program representing notional transmission network between three countries. 


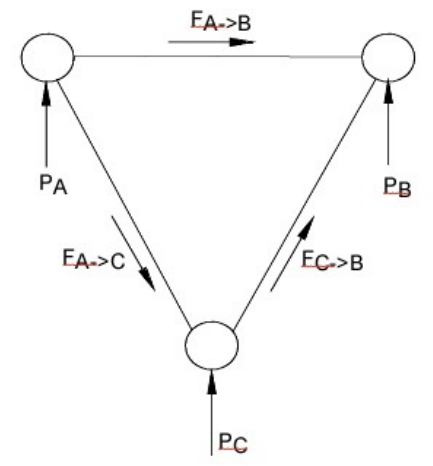

$\min \mathbf{m c}^{T} \cdot \mathbf{g}$

s.t. $\mathbf{B} \cdot \boldsymbol{\theta}-\mathbf{g}+\mathbf{d}_{0}-\mathbf{w}=0$

$$
\begin{aligned}
& -\mathbf{f}^{+} \leq \mathbf{H} \cdot \boldsymbol{\theta} \leq \mathbf{f}^{+} \\
& \mathbf{g}^{-} \leq \mathbf{g} \leq \mathbf{g}^{+} \\
& \mathbf{0} \leq \mathbf{w} \leq \mathbf{w}_{0} \\
& \mathbf{e}_{A}^{T} \cdot\left(\mathbf{g}-\mathbf{d}_{0}+\mathbf{w}\right)=P_{A} \quad \forall A \\
& P_{A}=\sum_{B} F_{A \rightarrow B} \forall A \\
& -T T C_{B \rightarrow A} \leq F_{A \rightarrow B} \leq T T C_{A \rightarrow B} \forall A, B
\end{aligned}
$$

where the new symbols are:

$F_{A->B}$ : Flow in the notional network between from country $A$ to $B$

$P_{A}$ : Net generation in country $A$

$\mathbf{e}_{\mathrm{A}}$ : Vector to select buses belonging to country $A$.

Criteria for TTC computation should be consistent with its use in dispatching. The methodology above clearly fails on these criteria. TTC computation makes full use of the available network (for instance, the computed TTC between France and Germany assumes that the Belgian, Dutch, Swiss and other networks are also used). In this regard it is expected to be close to the maximum sensible value. On the other hand, this relatively large TTC value is allocated to entities connecting just France and Germany, that is, the set of circuits physically linking France and Germany or the branch in the notional network joining France and Germany. Therefore this value is likely to be overgenerous. Even so, the TTC constraints are binding in many simulated scenarios.

In summary, the MADRID model provides a conservative (e.g., lower bound) estimate of the benefits of moving from TTC type congestion management to a nodal pricing regime which incorporates dispatch management. This is because the TTC simulations are based on two 
favourable assumptions. First, generous TTC values are assumed. Second, the system operators are assumed to be able to call on the least cost power stations when re-dispatching the system to address internal constraints, and only need to pay the marginal price for each station rather than market clearing price or premia for opportunity costs or market power.

\section{A.4 Calculation of the TTC capacity in the DRESDEN model}

This TTC calculation approach follows "Method C" of Section A.1 using an economic dispatch model with DC load flow constraints. In order to calculate the TTC between neighbouring countries, the nodal pricing model (1) is extended by equation set (5). Each country is characterized by a specified net export position netexport ${ }^{B C E}$, which corresponds to an agreed base case (BCE) and defined international transactional exchanges. To allow an adjustment of the net export position, the parameter $\Delta$ netexport is introduced and successively increased in country $A$ and decreased in country $B$ during the calculation procedure. The change in the net export position of a country has to be counterbalanced by the generation dispatch.

$$
\begin{aligned}
& \mathbf{e}_{A}^{T} \cdot \mathbf{g}-\mathbf{e}_{A}^{T} \cdot \mathbf{d}_{0}=\text { netexport }_{A}^{B C E}+\Delta \text { netexport }_{A}^{A \rightarrow B} \quad \forall A \\
& \Delta \text { netexport }_{B}^{A \rightarrow B}=-\Delta \text { netexport }_{A}^{A \rightarrow B}
\end{aligned}
$$

where the new symbols are:

$\mathbf{e}_{\mathrm{A}}$ : $\quad$ Vector indicating the nodes of country $A ;+1$ if node belongs to country $A$ netexport ${ }_{A}^{B C E}$ : Base case net export position of country $A$ $\Delta$ netexport ${ }_{A}^{A}{ }_{A}: \quad$ Increase of net export position of country $A$ for border $A \rightarrow B$.

The calculation procedure works as follows. In the first step the generation dispatch and power plant status is optimized for a defined base case. In order to determine the additional bilateral exchanges, the net export position of two neighbouring countries is changed (a stepwise increase of $\Delta$ netexport in one country and vice versa).

The unit commitment $\mathbf{u}$ and the dispatch of power plants $\mathbf{g}$ in both countries is optimized using an economic dispatch. The unit commitment in the remaining countries is fixed to the base case commitment whereas re-dispatching of power plants is allowed. The demand is fixed at the initial demand $\mathbf{d}_{\mathbf{0}}$ and not changed during the optimization procedure. If a feasible commitment and dispatch is found, the calculation procedure continues and the net export position is further increased or decreased respectively. Otherwise the procedure stops and the total 
increase of bilateral exchanges ( $\triangle$ netexport) reflects the maximum additional exchange $(\triangle E)$ according to the TTC definition.

The calculation procedure is performed for each combination of neighbouring countries. Finally, the total transfer capacity (TTC) is calculated as the initial transfer of the base case plus the maximum possible additional transfer $\Delta$ netexport following the definition in Annex A.1. The calculated total transfer capacity reflects the maximum exchange, which can be technically managed by the national power systems through adjustments of generation commitment and dispatch. Corresponding generation costs can be considered as an additional economic criterion for the determination of the maximum allowable additional exchanges.

Given the calculated total transfer capacity between European countries, the unit commitment and dispatch of power plants are optimized in two steps. Firstly, the unit commitment of power plants is optimized subject to limitations on international trade. The total transfer capacity represents the upper limit on international trades between neighbouring countries. Physical international and national network constraints are not considered, as international trades refer to transactional exchanges between European countries. This step represents the stylized dayahead market procedure in most European countries. The mixed integer linear program is as follows:

$\min \mathbf{m c}^{T} \cdot \mathbf{g}$

s.t. $\mathbf{P E} \cdot \mathbf{e}-\mathbf{P E} \mathbf{E}^{T} \cdot \mathbf{e}-\mathbf{g}+\mathbf{d}_{0}-\mathbf{w}=0$

$$
\begin{aligned}
& \mathbf{u} \cdot \mathbf{g}^{-} \leq \mathbf{g} \leq \mathbf{u} \cdot \mathbf{g}^{+} \\
& \mathbf{0} \leq \mathbf{w} \leq \mathbf{w}_{0} \\
& 0 \leq \mathbf{e}_{A}^{T} \cdot \mathbf{P E} \cdot \mathbf{e}_{B} \leq T T C_{A \rightarrow B} \quad \forall A, B
\end{aligned}
$$

where the new symbols are:

\section{e: $\quad$ Vector with ones \\ PE: Exchange variables between nodes of the network}

The power plant dispatch is optimized in the second step using the nodal pricing model (1) subject to physical network constraints (power flow limitations and DC load flow constraints). Hence physical network congestion is introduced and has to be managed using short-term congestion alleviation methods in the form of re-dispatch of power plants. However, the flexibility of power plants is limited as the unit commitment is fixed to the values of the first optimization step. The exception is that the unit commitment of fast starting gas-turbine power 
plants is not fixed due to their technical flexibility. Beside the power plant dispatch, wind spilling and load shedding are introduced as additional short-term congestion alleviation options. 